\title{
Field Power Measurements of Imaging Equipment
}

Marla McWhinney, Gregory Homan, Richard Brown, Judy Roberson, Bruce Nordman, John Busch

\author{
Energy Analysis Department \\ Environmental Energy Technologies Division \\ Ernest Orlando Lawrence Berkeley National Laboratory \\ University of California \\ Berkeley CA 94720, USA
}

May 2004

The work described in this paper was supported by the Office of Atmospheric Programs, Climate Protection Partnerships Division of the U.S. Environmental Protection Agency and prepared for the U.S. Department of Energy under Contract No. DE-AC0376 SF00098. 
This document was prepared as an account of work sponsored by the United States Government. While this document is believed to contain correct information, neither the United States Government nor any agency thereof, nor The Regents of the University of California, nor any of their employees, makes any warranty, express or implied, or assumes any legal responsibility for the accuracy, completeness, or usefulness of any information, apparatus, product, or process disclosed, or represents that its use would not infringe privately owned rights. Reference herein to any specific commercial product, process, or service by its trade name, trademark, manufacturer, or otherwise, does not necessarily constitute or imply its endorsement, recommendation, or favoring by the United States Government or any agency thereof, or The Regents of the University of California. The views and opinions of authors expressed herein do not necessarily state or reflect those of the United States Government or any agency thereof, or The Regents of the University of California.

Ernest Orlando Lawrence Berkeley National Laboratory is an equal opportunity employer. 


\title{
Field Power Measurements of Imaging Equipment
}

\author{
Marla McWhinney, Greg Homan, Rich Brown, Bruce Nordman, Judy Roberson
}

\begin{abstract}
According to the U.S. Department of Energy, electricity use by non-PC commercial office equipment is growing at an annual rate of nearly $5 \%$ (AEO 2003). To help address this growth in consumption, U.S. EPA periodically updates its ENERGY STAR specifications as products and markets change. This report presents background research conducted to help EPA update the ENERGY STAR specification for imaging equipment, which covers printers, fax machines, copiers, scanners, and multifunction devices (MFDs).

We first estimated the market impact of the current ENERGY STAR imaging specification, finding over $90 \%$ of the current market complies with the specification. We then analyzed a sample of typical new imaging products, including 11 faxes, 57 printers and 19 copiers/MFD. For these devices we metered power levels in the most common modes: active/ready/sleep/off, and recorded features that would most likely affect energy consumption. Our metering indicates that for many products and speed bins, current models consume substantially less power than the current specification. We also found that for all product categories, power consumption varied most considerably across technology (i.e. inkjet vs. laser). Although inkjet printers consumed less energy than laser printers in active, ready and sleep-mode, they consumed more power on average while off, mostly due to the use of external power supplies. Based on these findings, we developed strategies for the ENERGY STAR program to achieve additional energy reductions. Finally, we present an assessment of manufacturer's ENERGY STAR labeling practices.
\end{abstract}




\section{Table of Contents}

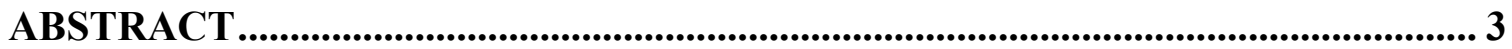

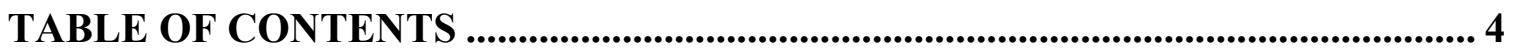

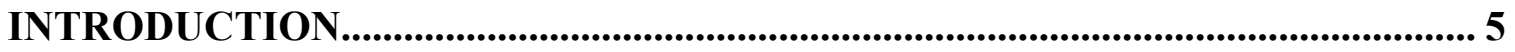

BACKGROUND .............................................................................................................. 6

ESTIMATING SAVINGS From OfFICE EQUIPMENT Power MANAGEMENT ........................ 6

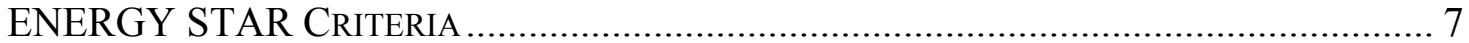

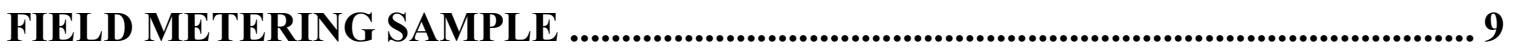

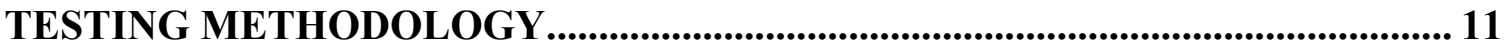

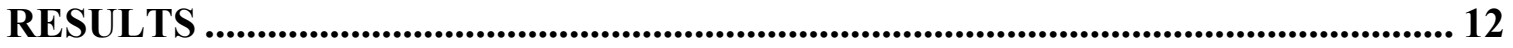

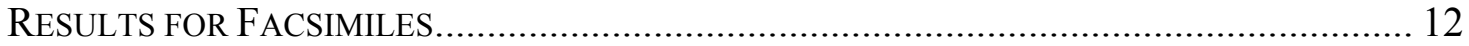

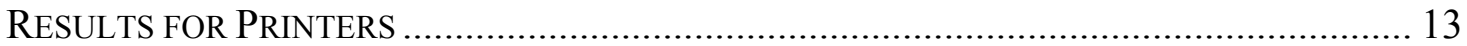

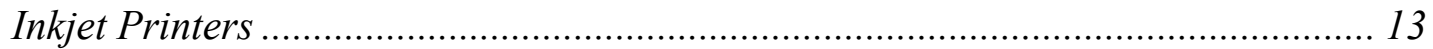

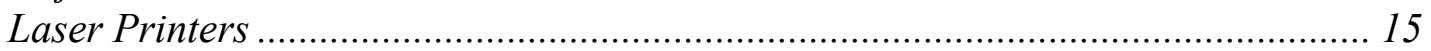

Distribution of power consumption by mode and print engine............................... 19

Effect of Duty Cycle on Total Annual Energy Consumption: Inkjet and Laser

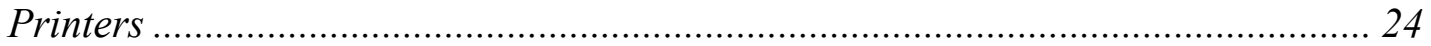

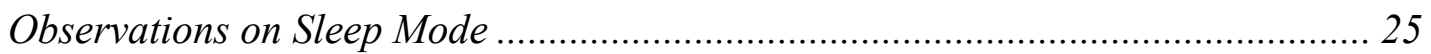

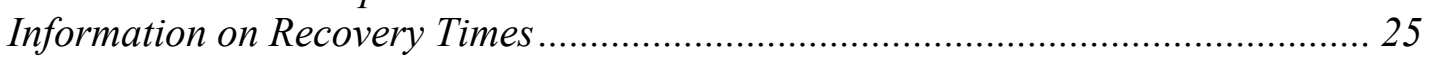

Comparison of Printer Data to Manufacturer Data ............................................. 26

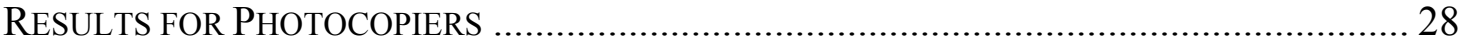

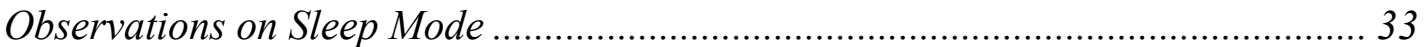

Comparisons of Photocopier Data to Manufacturer's Data ………......................... 33

MANUFACTURER LABELING PRACTICES................................................... 34

CONCLUSIONS ......................................................................................................... 35

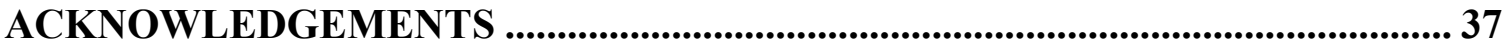

REFERENCES............................................................................................................ 37

APPENDIX A: PRODUCT SUMMARY OF FAX MACHINES............................. 39

APPENDIX B: METERING PROTOCOL................................................................. 40

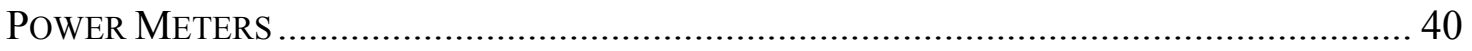

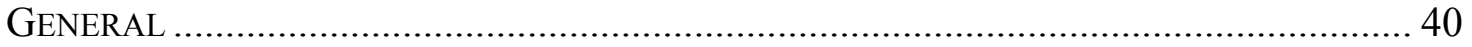

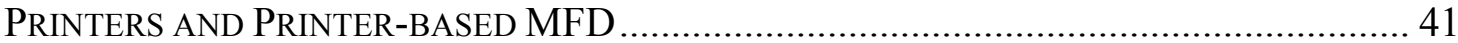

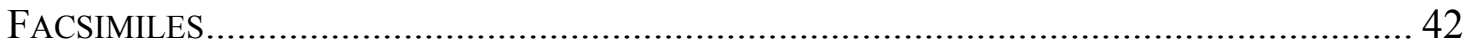

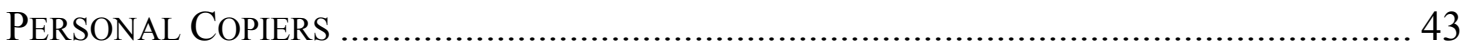

APPENDIX C: PRODUCT SUMMARY OF PRINTERS............................................ 45

APPENDIX D: PRODUCT SUMMARY OF COPIERS ................................................. 48

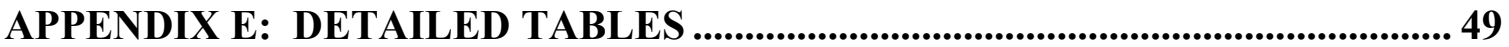




\section{Introduction}

Over the past twenty years, there has been persistent growth in the market for electronic commercial office equipment including personal computers (PC), monitors, copiers, fax machines, and scanners. In 2001, all commercial office equipment consumed 0.5 Quads, approximately $10 \%$ of commercial electricity (AEO 2003). The Department of Energy, reports a growth rate of $4.7 \%$ for non-PC commercial office equipment. This rate is more than double that of the total commercial electricity growth rate, 2.2\% (AEO 2003). To target and reduce office equipment consumption, ENERGY STAR launched the computer and monitor specification in 1992. Printers (1993), fax machines (1994), copiers (1995), scanners and multi-function devices (MFDs; 1997) were added to the ENERGY STAR program in subsequent years.

ENERGY STAR is a voluntary partnership between the U.S. Department of Energy (US DOE), the U.S. Environmental Protection Agency (US EPA), and industry. The primary goal of ENERGY STAR is to prevent air pollution by expanding the market for energyefficient products through the application of the ENERGY STAR label. The label is a mechanism that allows consumers to easily identify efficient products that save energy and money. By removing information barriers that affect purchasing decisions and by raising environmental awareness, ENERGY STAR stimulates demand for high-efficiency products and transforms the market over time.

To ensure that ENERGY STAR specifications achieve maximum savings and differentiation in the market, EPA updates existing specifications as the market changes. In 2003, EPA began background research to update the imaging equipment specification ${ }^{1}$.

To help support the specification evaluation, we assembled a dataset of imaging products including 11 faxes, 57 printers and 19 copiers in which we metered the most common modes including active/ready/sleep/off as well as recorded features that would most likely affect energy consumption. We then compared measured power levels to current ENERGY STAR power management criteria and manufacturer-reported power levels. Although labeling is not a product requirement, we wanted to estimate how visible the ENERGY STAR label is to the consumer. For models metered in a retail setting, we checked the product for the presence of an ENERGY STAR label.

This reports presents the methodology and results of field power measurements for imaging equipment. Our results will be used for the following purposes. First, our measurements will be used to improve Office Equipment program savings estimates. Second, our field survey and measurements will be used to improve ENERGY STAR imaging equipment program implementation. Finally, our measurements will be used in a limited way to inform revisions of the ENERGY STAR criteria for these products. The data is somewhat restricted in drawing conclusions regarding new ENERGY STAR

\footnotetext{
${ }^{1}$ Imaging equipment is part of the ENERGY STAR agreement between US EPA and the European Union (EU). U S EPA works collaboratively with the EU in updating the ENERGY STAR imaging specification.
} 
criteria for the following reasons: our metering includes both new and older (some discontinued) models and we only focused on field measurements and did not conduct any technical analysis to determine product design or design trends within individual models. As such, our measurements represent a snapshot of the current market.

\section{Background}

The following information provides additional context in which to interpret the results of our metering.

\section{Estimating Savings from Office Equipment Power Management (taken directly from Roberson, J. et al 2001)}

For each category of office equipment, reliably estimating the energy saved by power management depends on assessing the following factors as accurately as possible:

- Total equipment stock (calculated from estimated annual shipments and equipment lifetime),

- Average power consumption in each operating mode (off, on and ready/sleep power later defined in this report)

- Typical usage patterns (percent of time the equipment spends in each operating mode), and

- Power management success rates (the percent of equipment in which power management is present, enabled, and functional)

The last three factors can be combined to yield a typical unit energy consumption (UEC), which when multiplied by equipment stock provides an estimate of total annual energy consumption. Comparing this with estimated energy consumption in absence of power management provides annual savings from power management (Kawamoto et al., 2001, Nordman et al, 2000).

Office equipment manufacturers that participate in the ENERGY STAR program regularly provide EPA with a list of compliant models (i.e., those that meet the criteria and are therefore eligible for the ENERGY STAR label) and their relevant characteristics, including power used in each power mode. This information is compiled in a database used by the government to evaluate program achievements and complemented by data collected by LBNL, including field surveys of office equipment usage patterns and enabling rates, and field measurements of power consumption (Nordman et al, 1996).

The purpose of this study was to provide reliable data on the energy consumption of new imaging equipment that EPA can use to evaluate revisions to current ENERGY STAR criteria as well as to improve the accuracy of ENERGY STAR program savings estimates. 


\section{ENERGY STAR Criteria}

For each ENERGY STAR product, a unique specification describes the energy performance requirements that a product must meet to qualify for the label. One principle of EPA's ENERGY STAR program is that the specification represents the top $25^{\text {th }}$ percentile (quartile of units with the lowest power consumption) of energy-efficient products. As such, ENERGY STAR's Product Specification Development Team reassesses performance-based specifications as the market changes (McWhinney, $\mathrm{M}$ et al, 2003). In this section we present the current ENERGY STAR product definitions and criteria (see www.energystar.gov for more information) for imaging equipment product categories.

Copier- A commercial reprographic imaging unit whose sole function is the production of duplicates from a graphic hard copy original. A copier must include a marking system, an imaging system, and a paper-handling module. All black and white plain paper technologies are covered though the intent is to focus on widely used standard copier equipment such as light lens copiers. The specifications outlined below apply to standardsized copiers designed to handle A4 or 8.5" x 11" paper and large format copiers designed to handle A2 or 17" x 22" paper or larger. Covers analog copiers, digital copiers covered under MFD specification (US EPA, 1999).

Fax Machine - Imaging equipment, manufactured as a standard model, which serves as a hard copy output device whose primary function is sending and receiving information. Plain paper faxes are covered (bubblejet, inkjet, thermal, laser, LED). The unit is powered from a wall outlet. The product is marketed and sold as a fax machine (US EPA 2000).

Combination Printer/Fax Machine - Imaging equipment manufactured as a standard model that can serve as a fully functional printer or fax machine as defined by section II.A and II.B of the Printer/Fax MOU (see www.energystar.gov) (US EPA 2000).

MFD - A physically integrated device or a combination of functionally integrated components that produces hard copy duplicates from a graphically hard copy original (distinct from single sheet convenience copy) as well as performing one or both of the following functions: printing (from digital information received from networked computers, direct connect computers, file servers, or fax transmission), or faxing (send and receive), and may include scanning (to computer file) or any other functions. May be connected to network and may output black and white, gray scale or color. Covers products whose core function is copying (US EPA 1997). A product whose core function is faxing, but also offers convenience single sheet copying is covered under the fax MOU (US EPA 2000).

Printer - Imaging equipment, manufactured as a standard model, which serves as a hard copy output device, and is capable of receiving information from a single user or networked computers. In addition, the unit must be capable of being powered from a 
wall outlet. Intended to cover products sold as printers or that can be upgraded to MFDs (US EPA 2000).

In order to compare values from our metering directly to values reported by manufacturers and to be consistent with the current ENERGY STAR specification, we have simply adopted the power state definitions from the existing specification.

We define these states for the purposes of this report as follows:

Active: the condition in which the product is producing hard copy output or receiving hard copy input

Standby: the condition in which the product is not producing hard copy output or receiving hard copy input and is consuming less power than it would if producing such output or receiving such input. To clarify terminology we refer to this mode as "ready" in our report. We refer to the term as ready since standby can be interpreted a number of ways (can mean that a product is idle, can mean that a product is maintaining a service as in the case of water heaters, etc.) by manufacturers and the energy community. ENERGY STAR may want to consider revising the definition name as "ready" during this revision.

Low Power: not producing hard copy output, but is consuming less power than it would in standby power (may be some delay in the production of hard copy output)

Sleep: the condition in which the product is not producing hard copy output or receiving hard copy input and is consuming less power than it would in standby mode and low power mode (may be some delay in production of hard copy output). This is the lowest power mode without actually turning off.

Off: the condition in which the product is connected to the electrical source, but is not turned on. To turn the unit on, a person needs to manually start via the on/off switch. 
Table 1: Summary of ENERGY STAR Criteria

\begin{tabular}{|c|c|c|c|c|c|}
\hline Product Category & Speed Bin & Power Mode & Wattage & Power Mode & Wattage \\
\hline \multirow[t]{5}{*}{ BW Standard Printer \& Combination } & $0<\mathrm{ppm} \leq 10$ & Sleep & $\leq 10$ & - & - \\
\hline & $10<\mathrm{ppm} \leq 20$ & Sleep & $\leq 20$ & - & - \\
\hline & $20<\mathrm{ppm} \leq 30$ & Sleep & $\leq 30$ & - & - \\
\hline & $30<\mathrm{ppm} \leq 44$ & Sleep & $\leq 40$ & - & - \\
\hline & $\begin{array}{l}44<\mathrm{ppm} \\
\end{array}$ & Sleep & $\leq 75$ & - & - \\
\hline \multirow[t]{3}{*}{ Color Printer } & $0<\mathrm{ppm} \leq 10$ & Sleep & $\leq 35$ & - & - \\
\hline & $10<\mathrm{ppm} \leq 20$ & Sleep & $\leq 45$ & - & - \\
\hline & $20<\mathrm{ppm}$ & Sleep & $\leq 75$ & - & - \\
\hline Impact Printer & All & Sleep & 28 & - & - \\
\hline \multirow[t]{3}{*}{ Large/Wide Format } & $0<\mathrm{ppm} \leq 10$ & Sleep & 35 & - & - \\
\hline & $10<\mathrm{ppm} \leq 40$ & Sleep & 65 & - & - \\
\hline & $40<\mathrm{ppm}$ & Sleep & 100 & - & - \\
\hline \multirow[t]{2}{*}{ Facsimile Machine } & $0<\mathrm{ppm} \leq 10$ & Sleep & $\leq 10$ & - & - \\
\hline & $10<\mathrm{ppm}$ & Sleep & $\leq 15$ & - & - \\
\hline \multirow[t]{4}{*}{ Mailing Machine } & $0<\mathrm{mppm} \leq 50$ & Sleep & $\leq 10$ & - & - \\
\hline & $50<\mathrm{mppm} \leq 100$ & Sleep & $\leq 30$ & - & - \\
\hline & $\begin{array}{l}100<\mathrm{mppm} \leq 150 \\
\text { a }\end{array}$ & Sleep & $\leq 50$ & - & - \\
\hline & $150<\mathrm{mppm}$ & Sleep & $\leq 85$ & - & - \\
\hline \multirow[t]{3}{*}{ Standard Copier } & $0<\mathrm{cpm} \leq 20$ & Low & None & Off & $\leq 5$ \\
\hline & $20<\mathrm{cpm} \leq 44$ & Low & $3.85 \times \mathrm{cpm}+5$ & Off & $\leq 15$ \\
\hline & $44<\mathrm{cpm}$ & Low & $3.85 \times \mathrm{cpm}+5$ & Off & $\leq 20$ \\
\hline \multirow[t]{2}{*}{ Large Format Copier } & $0<\mathrm{cpm} \leq 40$ & Low & None & Off & $\leq 20$ \\
\hline & $40<\mathrm{cpm}$ & Low & None & Off & $\leq 40$ \\
\hline \multirow[t]{5}{*}{ Standard MFD } & $0<\mathrm{ipm} \leq 10$ & Low & None & Sleep & $\leq 25$ \\
\hline & $10<\mathrm{ipm} \leq 20$ & Low & None & Sleep & $\leq 70$ \\
\hline & $20<\mathrm{ipm} \leq 44$ & Low & $3.85 \times \mathrm{ipm}+50$ & Sleep & $\leq 80$ \\
\hline & $44<\mathrm{ipm} \leq 100$ & Low & $3.85 \times \mathrm{ipm}+50$ & Sleep & $\leq 95$ \\
\hline & $100<\mathrm{ipm}$ & Low & $3.85 \times \mathrm{ipm}+50$ & Sleep & $\leq 105$ \\
\hline
\end{tabular}

Notes:

1. $\mathrm{ppm}=$ pages per minute

2. $\operatorname{mppm}=$ mail pages per minute

3. $\mathrm{cpm}=$ copies per minute

4. $\mathrm{ipm}=$ images per minute

\section{Field Metering Sample}

In our sample of imaging equipment, we attempted to get a range of representative product models. The faxes in our dataset were metered at retail stores in February 2002 and consist of both fax only and fax/copy models with a top modem speed of $33.6 \mathrm{kBps}$. All fax models were manufactured in 2002 except the Brother Fax 2800 (which was manufactured in $2001\left(\right.$ June $\left.^{2}\right)$. See Appendix A for a listing of fax models metered.

For printers, there was an enormous amount of product diversity across speed bins and technologies, which was difficult to capture in our limited sample size. We attempted to meter several models for each print technology (i.e. inkjet vs. laser) and within each speed bin as defined by ENERGY STAR's current imaging specification (Table 2). Although the printer sample is spread across the various speed bins and technologies, it is weighted more heavily within the $10<\mathrm{ppm} \leq 20$ category. We focused on metering

\footnotetext{
${ }^{2}$ We do not have a manufacturing date for the Sharp UX-B700 fax.
} 
products manufactured in 2002; however, our sample was not as balanced as hoped due to the following difficulties:

\section{Table 2: Breakdown of Printer Sample}

\begin{tabular}{|c|c|c|c|c|c|}
\hline & All Printers & Inkjets & Laser & B \& W Laser & Color Laser \\
\hline Price Range & $\$ 50-\$ 3,799$ & $\$ 50-\$ 500$ & $\$ 250-\$ 3799$ & $\$ 250-\$ 3799$ & $\$ 800-\$ 1000$ \\
\hline \# Manufacturers & 8 & 5 & 6 & 3 & 4 \\
\hline Total Units & 57 & 33 & 24 & 15 & 9 \\
\hline $0<\mathrm{ppm}<=10$ & 9 & 7 & 2 & 2 & 4 \\
\hline $10<\mathrm{ppm}<=20$ & 39 & 23 & 16 & 7 & 5 \\
\hline $20<\mathrm{ppm}<=30$ & 5 & 3 & 2 & 2 & 0 \\
\hline $30<\mathrm{ppm}<=44$ & 3 & 0 & 3 & 3 & 0 \\
\hline $44<\mathrm{ppm}$ & 1 & 0 & 1 & 1 & 0 \\
\hline $\begin{array}{l}\text { Notes: } \\
\text { 1. We only had } \mathrm{p} \\
\text { 2. Print speeds f } \\
\text { 3. Print speeds f }\end{array}$ & $\begin{array}{l}\text { ta for } 42 \text { units. } \\
\text { ll, Inkjet, Tota } \\
\text { olor laser cates }\end{array}$ & $\begin{array}{l}\text { and BW } 1 \\
\text { lect color } \mathrm{p}\end{array}$ & $\begin{array}{l}\text { egories reflect } \\
\text { eds. }\end{array}$ & print speeds. & \\
\hline
\end{tabular}

- In the retail setting, many products did not have manufacturing dates. For these products, we recorded the date of the inventory sticker when available, or the date acquired by store if the sales person knew. In absence of this information, we recorded if the product was still a current model being marketed on the manufacturer's website at the time of testing.

- We had limited access to metering large office printers due to two factors: 1) these products are not available retail, 2) the length of time needed to record data for units that power-cycle (one hour metering protocol). These factors restricted us to metering equipment at LBNL. We metered equipment recently purchased by LBNL; however, some of the models recently purchased and included in the dataset are discontinued by the manufacturer and have been replaced by newer models. These discontinued models include: HP 8100, HP 1200se, HP 2200dn, HP 4000n, HP 4550dn, and Tektronics 750. Since we have a limited sample size for business-series printers, we have included these products in our data set. We also metered the HP G95 and HP G85 printer-based MFDs, which were also discontinued models. Since we have a larger sample of printer-based MFDs from the retail metering, we have not included these two models in the dataset.

We also made best attempts to meter a representative range of photocopiers.

The sample of photocopiers is limited due to several factors. The largest photocopiers have power supply capacities that exceed the rating of our power line meters, and could not be tested. Plug compatibility was an issue as well, as we encountered several devices with plugs that prevented testing with our standard meter, even when they did not exceed the meters rating. We were able to build an adapter that allowed us to test some machines that would otherwise have been incompatible, but we were not able to find off the shelf 
parts that would allow us to test all the machines to which we otherwise would have had access. Obtaining access to as wide a variety of machines as would have been ideal also proved problematic. For example, many types of photocopiers are not sold in showrooms, thus we were restricted to using devices where the owners were willing to participate in this study. As with other imaging devices, our emphasis was on models currently available, however the restrictions noted above lead to our including older models in the sample.

In addition to the relatively small sample of machines available we also encountered restrictions as to what modes we could meter. The copiers metered in retail outlets could not be put into active mode. Several of the operators for copiers metered at LBNL or at City of Berkeley (COB) put restrictions on what use we could make of their machines. For example one machine was in heavy use, so despite setting the sleep mode delay to its minimum setting we never observed this machine in sleep.

As with printers there is considerable variety among copiers. Although all speed bins were represented in our sample, the medium speed bin was underrepresented with only 2 of the 19 metered devices falling into this category. The sample contains 12 low speed units and 8 from the high-speed category. All devices were standard sized copiers, although most of the high-speed devices were capable of handling paper other than letter or A4, typically up to $11 \mathrm{X} 17$.

Our sample included three technologies, inkjet, electrostatic transfer and laser. The later comprised the majority of the sample, with one inkjet and two thermal type units included. We also tested two differently configured examples of a single model, one of which was configured as a stand-alone copier, the other a networked multi-function device.

\section{Testing Methodology}

Three field power line meters (PLMs) were used in our study. We used one $3 \mathrm{~A}$ and one 15 A meter to test at retail locations in Pittsburgh. We used one $15 \mathrm{~A}$ meter in combination with a laptop to test at LBNL in Berkeley. Power measurements were conducted using two methodologies: spot metering and time-series metering. Both metering methodologies measure the power consumption in watts over a short period (minutes to hours); however the time series method utilizes a laptop to record the data electronically (readings recorded approximately every two seconds). The data is later downloaded into a spreadsheet for subsequent statistical analysis. We also recorded product features that would most affect energy consumption (connectivity, print/copy speed, power supply). See Appendix B for details on the test methodology.

Printers were tested at retail locations or at LBNL using either the time-series or manual test method. The metering methodology and location depended on the type of printer. For small home printers, we metered in stores using spot metering. For larger, businessseries laser printers, we metered at LBNL using the time-series method. 
Printers tested in a retail setting consisted primarily of inkjet printers, inkjet printer-based MFDs, and small laser printers for home/small business use. The small laser printers were typically equipped with instant-on fuser technology. Because these products were spot metered, measurements do not capture any cycling, if present, during the readymode for the laser models.

Printers metered at LBNL were primarily business-series laser printers equipped with traditional fuser technology. When the unit enters ready-mode, the fusers cycle on and off to maintain a temperature in order to be partially ready for the next print job. This cycling causes fluctuations in power during the ready-mode. In order to capture this cycling in our measurements, we recorded the electronic data from the PLM for subsequent analysis. See Appendix C for a summary of printer models metered along with the testing methodology used for each product model.

The photocopiers in our sample were metered at retail locations, at LBNL and at the City of Berkeley (COB) administrative offices. Copiers tested in retail locations were metered manually as per Appendix B. The copiers tested at LBNL and COB was metered with the datalogger using a method like that used for large laser printers. Where possible an hour of 'ready' time was obtained as well as time in low power modes.

Power measurements were recorded in tenths of a watt, and the results of our calculations are rounded and reported to the nearest watt. Accuracy for the meters is to the tenth of a watt.

Measurements of the time needed to recover from sleep mode are subjective and should be viewed as order-of-magnitude estimates. Recovery times were recorded to the nearest second. Recovery time began with a wake event and ended when the researcher to his/her best knowledge judged the unit to be capable of performing its intended function. Currently, the ENERGY STAR criteria lacks a test procedure for measuring recovery time. This presents several complications in interpreting our results. In the case of laser printers and digital copiers, the 'ready' button may not indicate that the unit will begin printing immediately, but rather that the unit is only ready to begin preparing the image for printing. Also, there is a question as to whether or not the unit was at ambient temperature when the recovery event took place. If the unit was not at ambient temperature, the recovery time will be shorter than in actual operating conditions. These difficulties suggest a strong need for a test procedure in the revised specification.

\section{Results}

The remainder of the memo summarizes results from the imaging equipment metering.

\section{Results for Facsimiles}

We metered 11 faxes at two retail locations. Products represent four different manufacturers. Even though the current ENERGY STAR specification has a default to sleep time, we found that only one model had a separate sleep setting accessible through 
the menu panel (Brother Fax 4100). All other faxes were metered in ready mode in which the time and date was typically displayed on the unit. Figure 1 summarizes our results. One hundred percent of the sample met the current ENERGY STAR specification of $10 \mathrm{~W}$. Approximately $35 \%$ of the sample consumed four watts or less in the ready mode. The Brother Fax 4100 consumed the same amount of power in sleep as it did in the ready-mode $(7 \mathrm{~W})^{3}$.

We metered 6 inkjets, 3 thermal, and 2 laser faxes and found variation by technology with the corresponding ready-mode measurements as follows: 4, 3W, $8 \mathrm{~W}$ (measurements represent top quartile of energy efficient products). All faxes in our sample used internal power supplies.

\section{Figure 1: Distribution of Fax Ready Power}

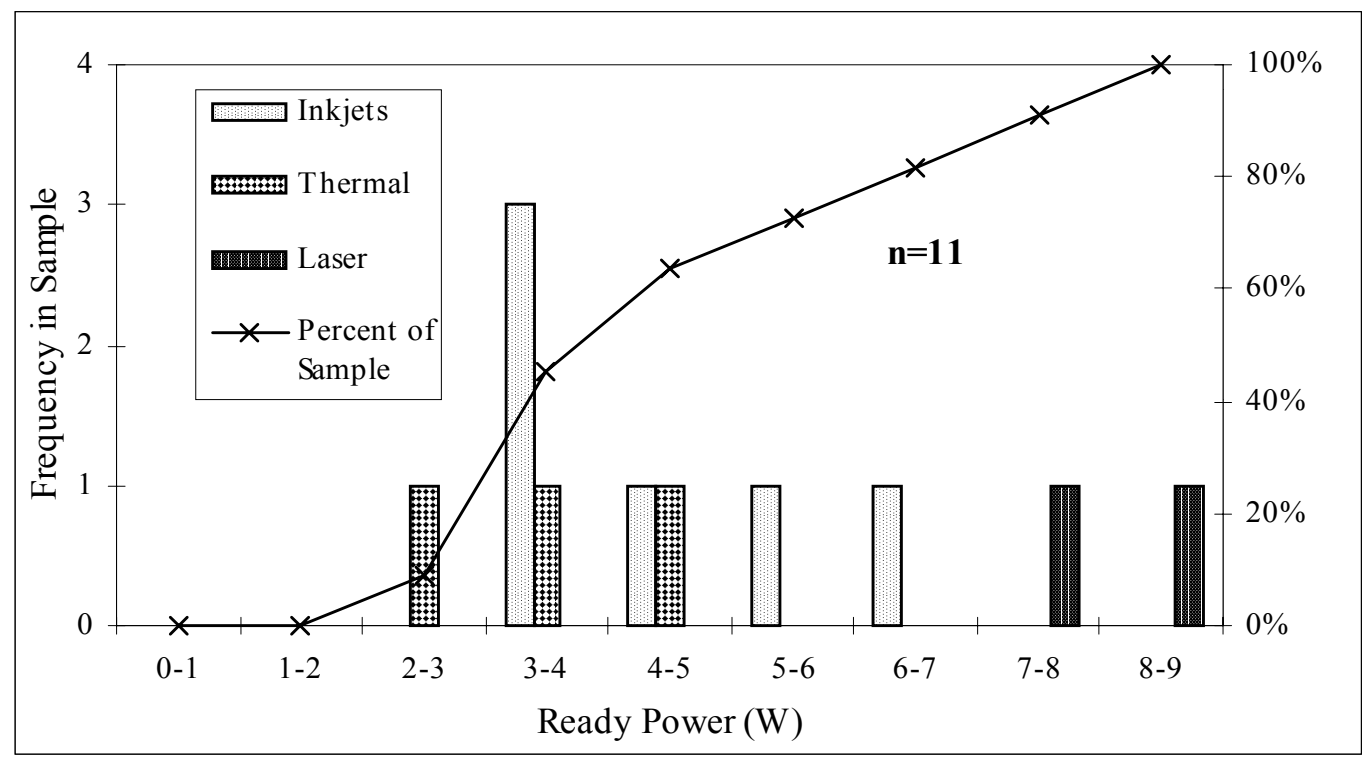

\section{Results for Printers}

We metered a total of 57 printers representing eight manufacturers with product prices ranging from $\$ 50$ to $\$ 3,799$ (Table 2). Results from the analysis are summarized below.

In our testing, we found that variation in ready and sleep-mode power was most substantial across print engine technologies (i.e. inkjet vs. laser). To analyze and account for this variation, we disaggregated our results into inkjet and laser printing categories.

\section{Inkjet Printers}

In our sample of 57 printers, 33 models were standard size inkjets. Ninety four percent of inkjets qualify for the ENERGY STAR program based on current specifications. Our sample consisted of the following: 21 print-only units, and 12 printer-based MFDs.

\footnotetext{
${ }^{3}$ This product appeared to go to sleep due to its display reading, "sleep".
} 
Figure 2 shows results for inkjet print-only devices (top quartile of energy efficient models).

\section{Figure 2: Results for Print-only Inkjets}

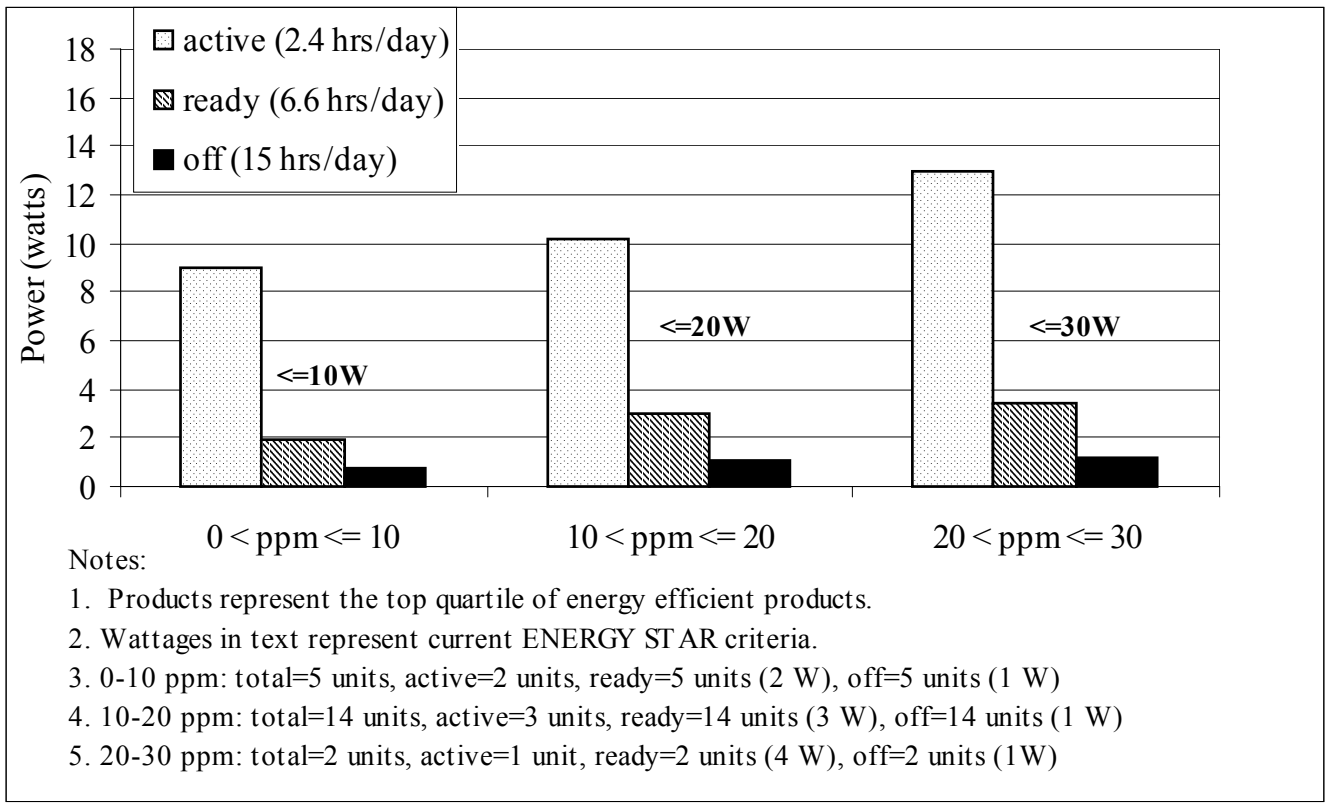

Because ENERGY STAR identifies the top quartile of energy efficient products during the specification revision, we present those results in our figures. Summary results for entire printer sample can be found in Appendix E. Our results show that the top quartile of energy efficient models fall significantly below the current ENERGY STAR criteria for each speed bin. For the most efficient quartile of products, we found that ready-mode power consumption varied from 2 watts to 4 watts across the $0-10 \mathrm{ppm}$ and 20-30 ppm speed bins.

In our analysis of inkjet MFDs, we found that six units had a separate sleep-mode setting. By separate sleep-mode setting, we simply mean that a "power save" setting was available in the control menu, which we activated during our metering. To analyze inkjet MFDs, we divided our sample in two categories: units with a sleep-mode setting in the control menu and units without a sleep-mode setting in the control menu (Figure 3).

For all speed bins greater than $10 \mathrm{ppm}$, we found that current power levels for the top quartile of energy efficient products (ready-mode for models with no sleep setting in the control menu and sleep-mode for products with a sleep setting in the control panel) fell substantially below the current ENERGY STAR specifications. In the case of products with a sleep setting, there was little difference between ready and sleep-mode power levels for the top quartile of energy efficient products. 
Figure 3: Results for Inkjet Printer-Based MFDs
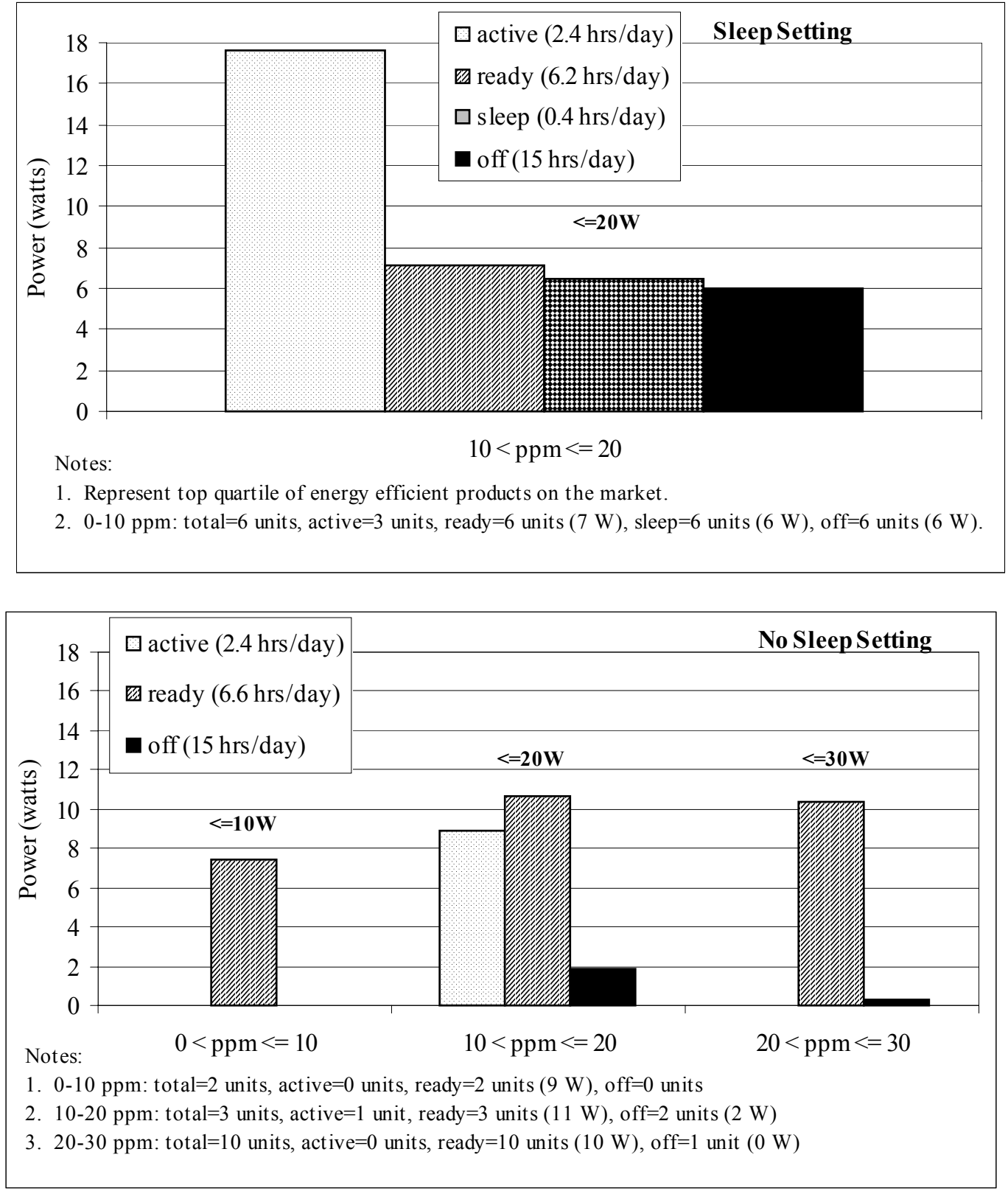

\section{Laser Printers}

We tested a total of 24 laser printers. In our sample, 91\% of all laser printers met the current ENERGY STAR specification.

Figure 4 demonstrates that for monochrome laser printers without a sleep setting, power consumption in the ready-mode was substantially less than the current ENERGY STAR criteria across the $10<\mathrm{ppm} \leq 20$ speed bins. 
Similarly, for models with a sleep-mode setting, power consumption in the sleep-mode was substantially less than current ENERGY STAR criteria for the top quartile of energy efficient products for all speed bins greater than $10 \mathrm{ppm}$.

Our results show that active, ready, and sleep-mode power consumption varies across speed bins beginning at the 20-ppm and higher category. Our metering indicates lower active power for the $+44 \mathrm{ppm}$ category (where we only had one unit in our sample) compared to the 30-44 ppm category. This result is likely indicative of the power consumption for one particular model rather than an overall trend for the entire speed bin. Off power was consistently low ( $\sim 0 \mathrm{~W})$ due to the primary use of internal power supplies.

\section{Figure 4: Results for Monochrome Laser Printers}

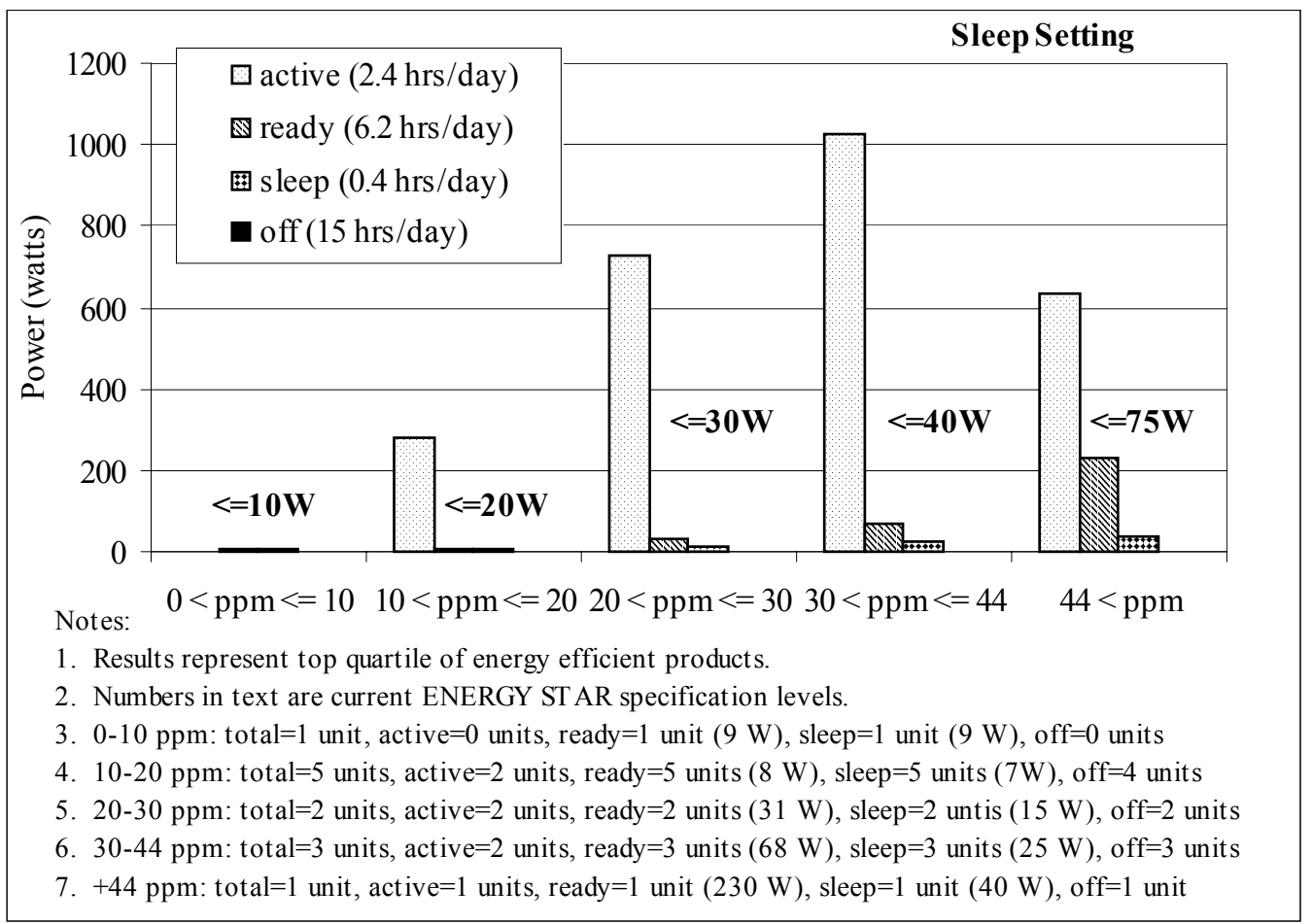


Figure 4: Results for Monochrome Laser Printers (continued)

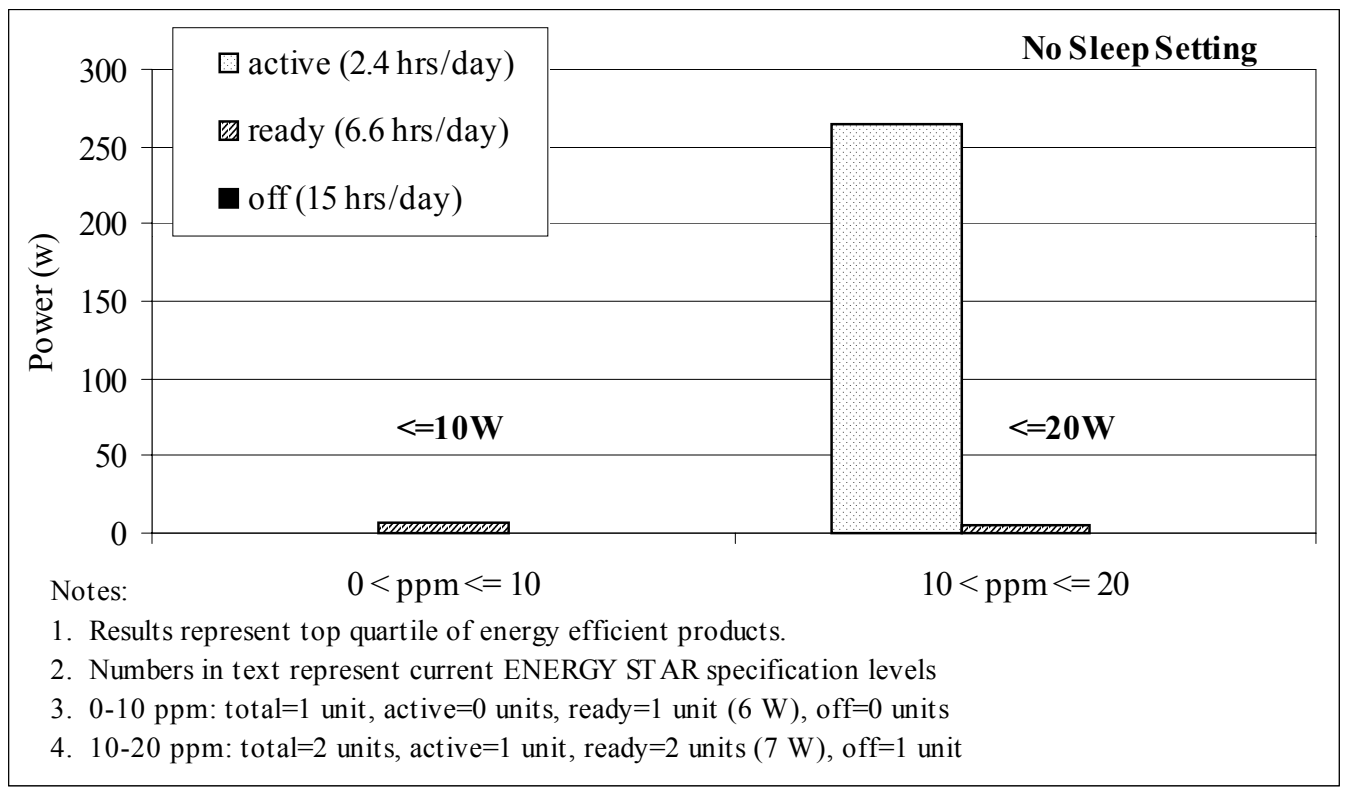

Figure 5 shows results for color laser printers. Results are categorized by color print speeds.

Again, for color laser printers with a sleep-mode setting in the control panels, sleep-mode consumption was considerably lower than the current ENERGY STAR criteria ${ }^{4}$. Although we found ready-mode power to increase between the 0-10 ppm and 10-20 ppm category, we found sleep power to remain relatively constant. Off power was again close to 0 Watts due to the use of internal power supplies.

\footnotetext{
${ }^{4} \mathrm{We}$ only had one sample in each speed-bin for color printers without sleep-mode settings.
} 


\section{Figure 5: Results for Color Laser Printers}
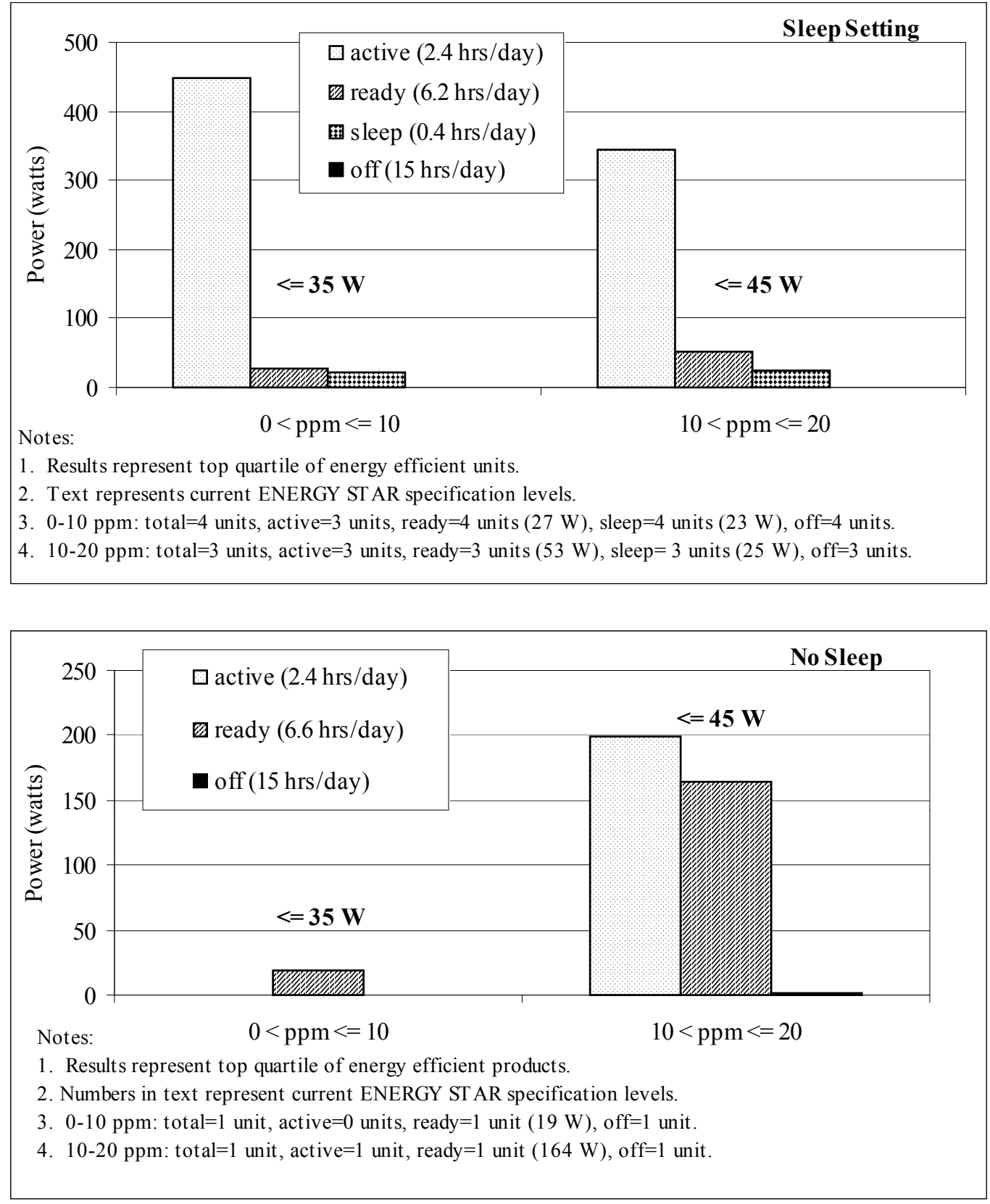
In this section, we disaggregate our metering results by print engine and print mode. The following figures demonstrate the changing distribution of power consumption by printmode and print-engine.

Figure 6 shows the following:

- Inkjet printers tend to have much lower active power and ready power levels compared to both color and monochrome laser printers. For inkjets, ready power increases as active power increases.

- For monochrome laser printers, we found a limited relationship between active and ready power

- $10-20$ ppm: average active power $=284 \mathrm{~W}$, average ready power $=37 \mathrm{~W}$

- 20-30 ppm: average active power $=786 \mathrm{~W}$, average ready power $=43 \mathrm{~W}$

- $30-44 \mathrm{ppm}$ average active power $=1125 \mathrm{~W}$, average ready power $=119 \mathrm{~W}$

- We did not find a relationship between active and ready power for color laser printers.

Figure 6: Distribution of Active Power vs. Ready Power by Print Engine

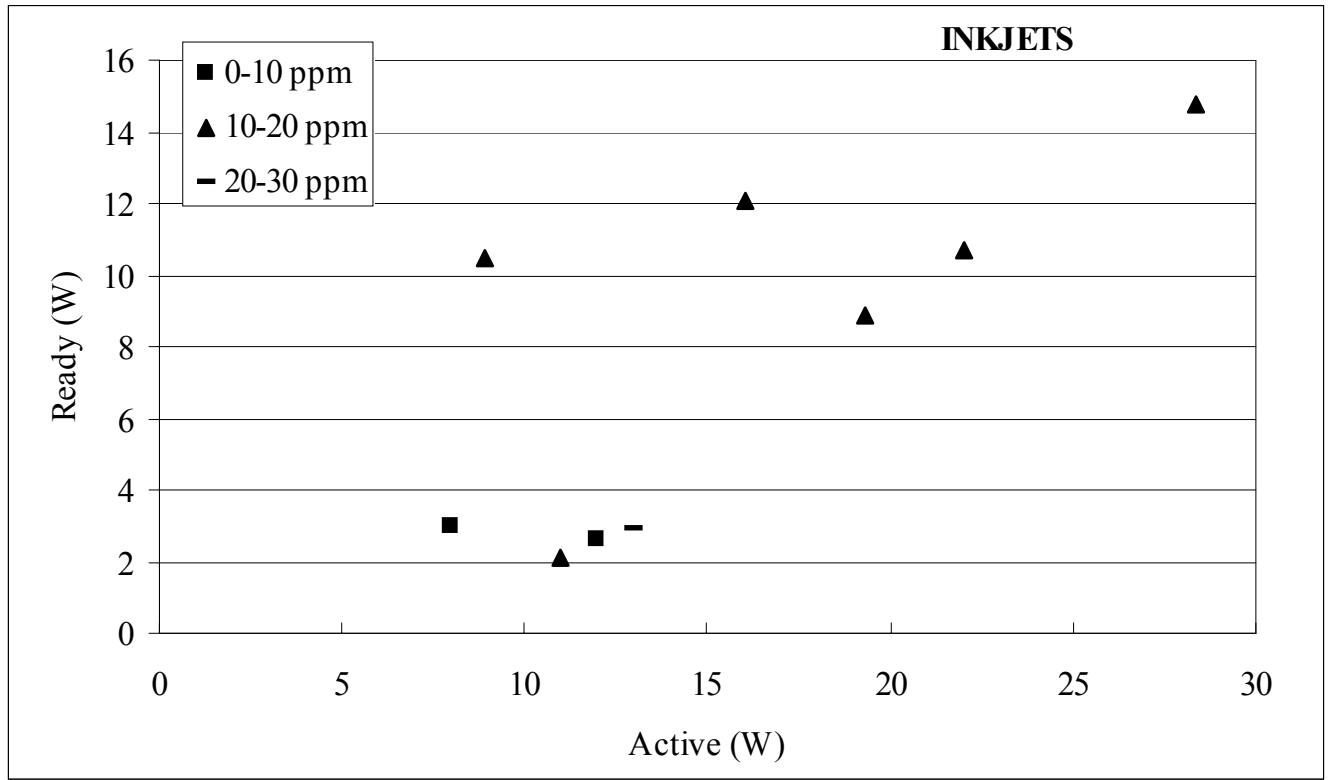


Figure 6: Distribution of Active Power vs. Ready Power (Continued)
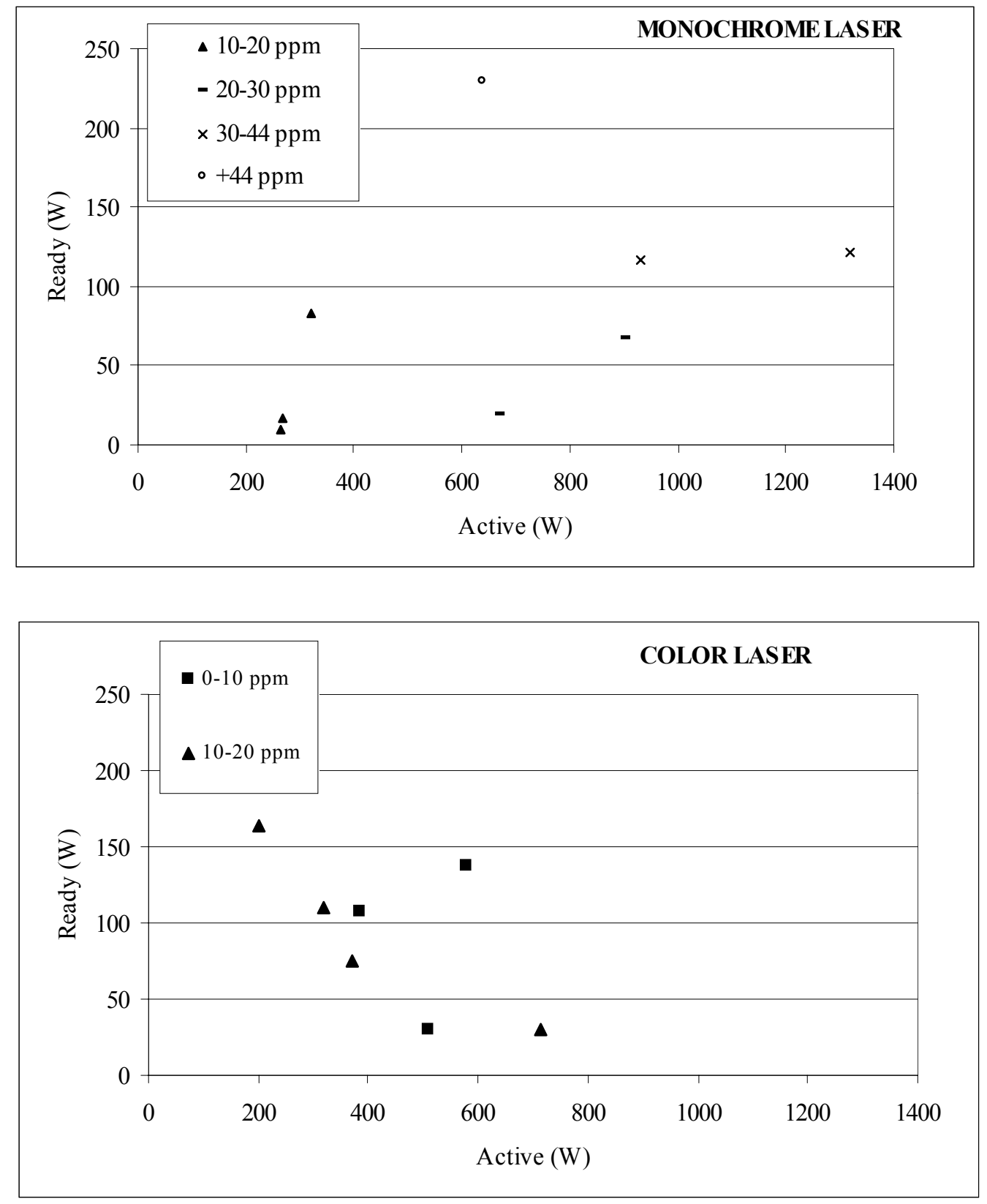

Figure 7 shows the distribution of active power vs. sleep-mode power consumption by print-mode. Our results indicate the following:

- In the 10-20 ppm category, inkjet MFDs have much lower active power than laser printers.

- We found little variation in average active to sleep-mode comparison for color printers between the 0-10 ppm (average active power $=491 \mathrm{~W}$ and average sleep 
power $=31 \mathrm{~W}$ ) and 10-20 ppm (average active power $=468 \mathrm{~W}$ and average sleep power $=30 \mathrm{~W}$ ) speed bins.

- For monochrome printers, we found that models with that products in the two highest speed bins consumed the most power in sleep mode.

Figure 7: Distribution of Active Power vs. Sleep Power by Print Engine
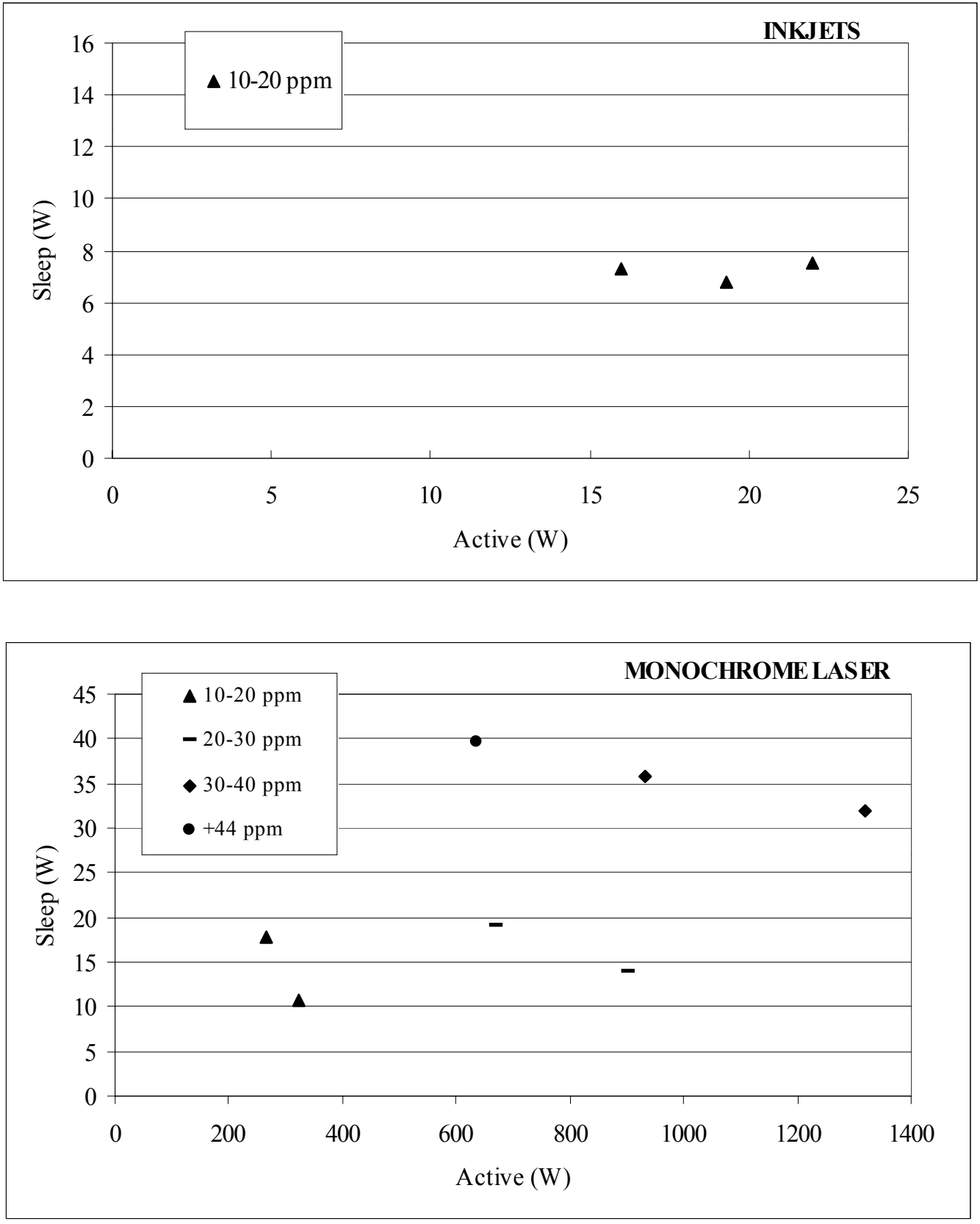
Figure 7: Distribution of Active Power vs. Sleep Power (Continued)

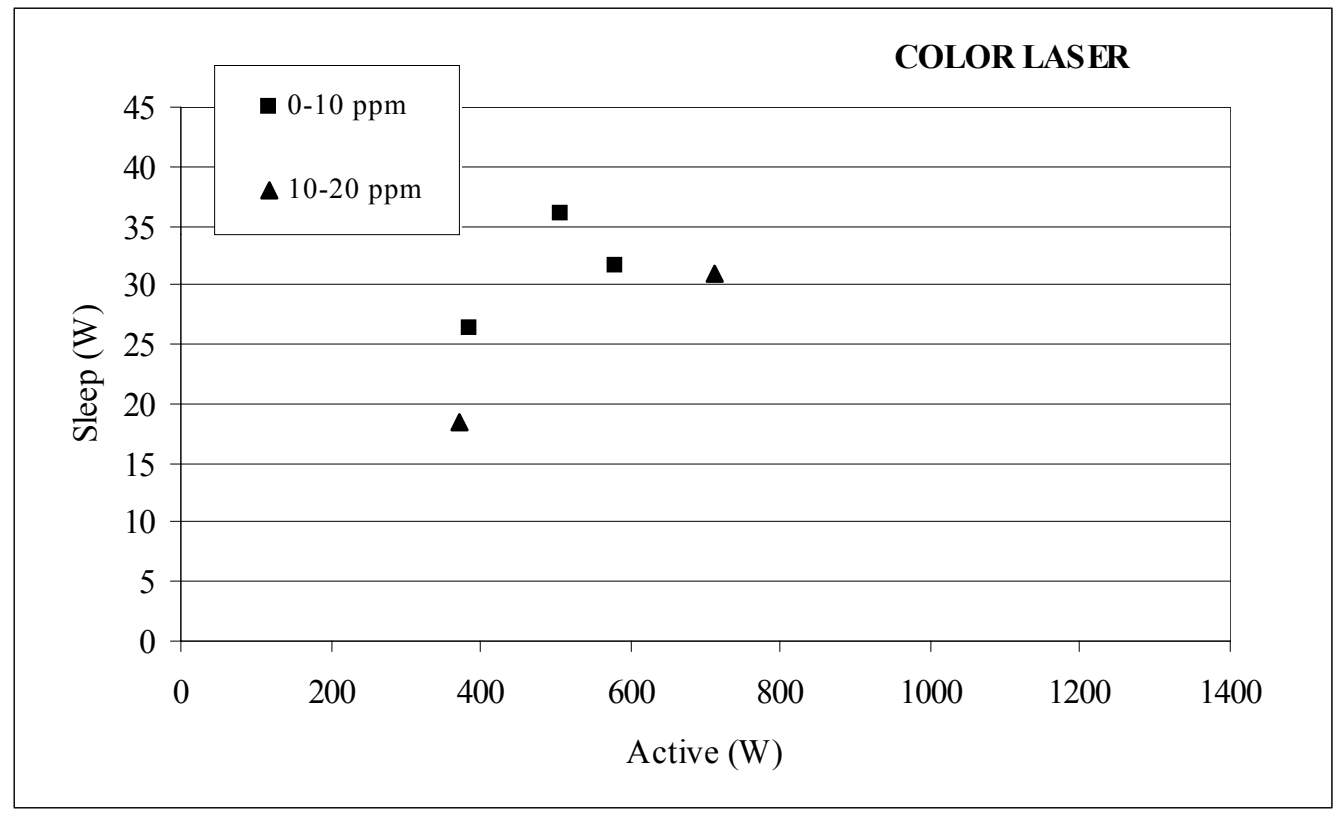

Figure 8 shows the distribution of ready power vs. sleep power by print engine. We found the following results:

- Again, inkjet printers have comparatively small range of ready power in the $10-20$ ppm category compared to laser printers. As ready power increases, sleep power also increases slightly.

- For monochrome printers, the 30-44 ppm and $+44 \mathrm{ppm}$ category tended to have the highest ready power levels. These high levels also corresponded to higher sleep levels.

- For color laser printers, there is a substantial distribution around both ready and active power measurements within the $0-10$ and $10-20 \mathrm{ppm}$ speed bins. 
Figure 8: Distribution of Ready Power vs. Sleep Power by Print Engine
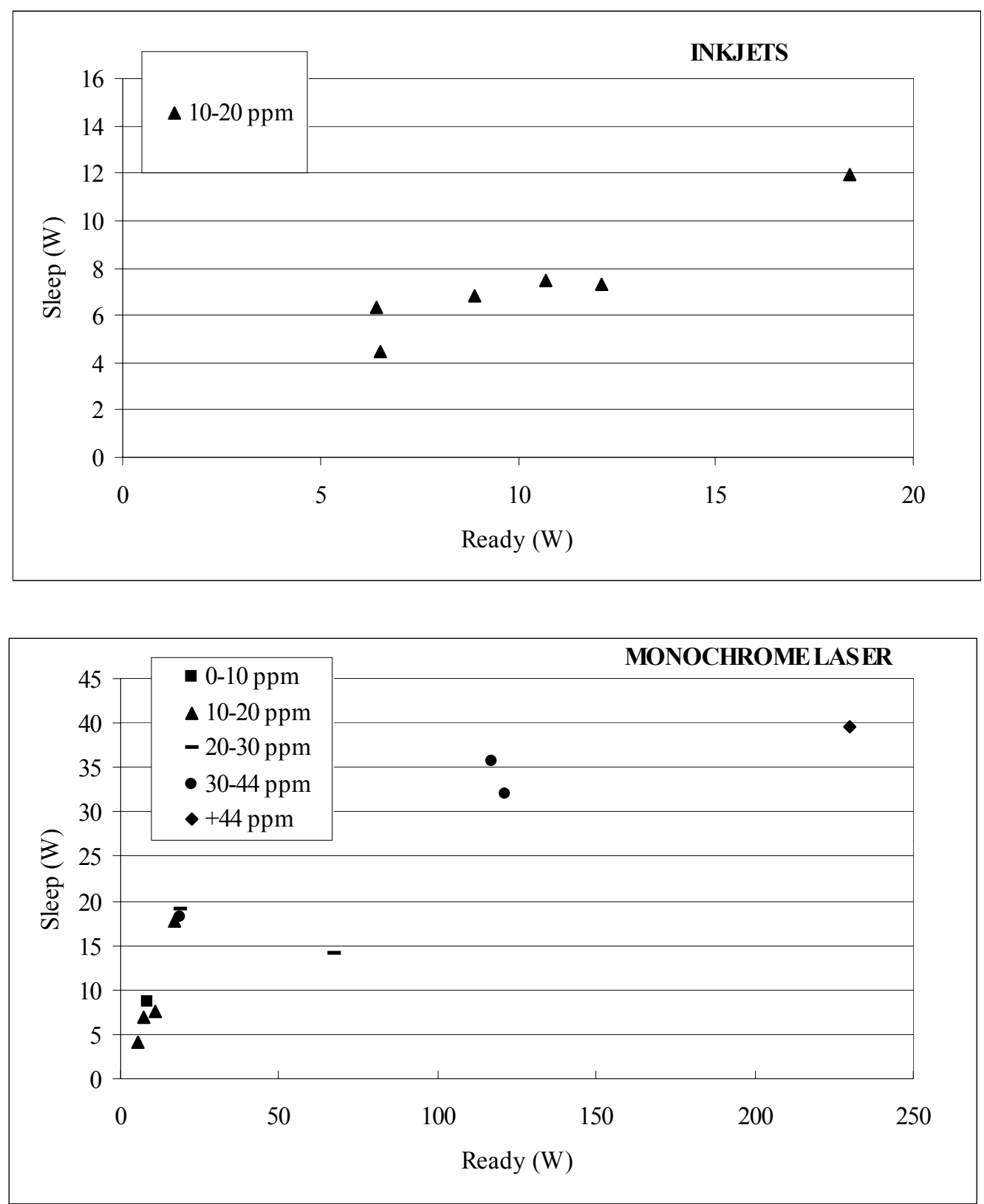
Figure 8: Distribution of Ready Power vs. Sleep Power by Print Engine (continued)

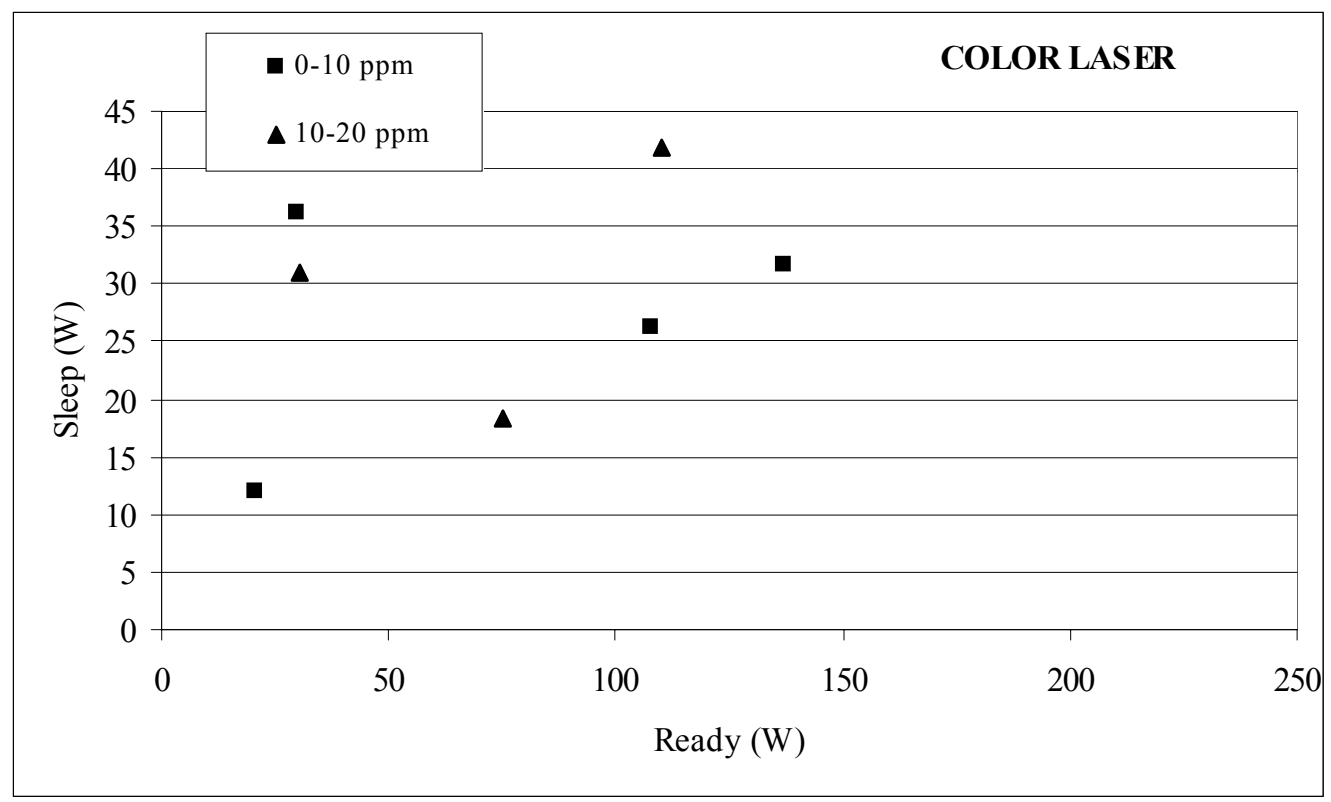

Effect of Duty Cycle on Total Annual Energy Consumption: Inkjet and Laser Printers

In general, we found that inkjets drew substantially less power in active-mode than laser printers.

We found that (on average) inkjets drew more power in off-mode across all speed bins when compared to monochrome printers (average off power for inkjets in each speed $\mathrm{bin}=2 \mathrm{~W}$, average off power for lasers in each speed bin $=0$ ). The difference in off-mode consumption is due primarily to the use of external power supplies in inkjet printers. In our total sample of inkjet printers, we found that 15 out of 33 models were equipped with external power supplies. The average off-mode consumption for products with external power supplies in our sample was $4 \mathrm{~W}$. The average off-mode consumption for products with internal power supplies was $2 \mathrm{~W}$.

Requiring the use of internal power supplies or placement of the off switch on the primary side of the circuit is one possible efficiency measure to reduce inkjet energy consumption.

Table 3 shows the overall effect of these differences in power consumption on total annual energy consumption and potential savings for inkjet vs. laser printers based on our metering. 
Table 3: Summary of Annual Energy Consumption for Printers

\begin{tabular}{|c|c|c|c|c|c|c|c|c|c|c|c|}
\hline & Act & e (W) & Stan & y (W) & Sleep & $p(W)$ & & $(\mathbf{W})$ & & $(\mathbf{k W h} / \mathbf{y r})$ & Savings \\
\hline & mean & $\begin{array}{c}25 \text { th } \\
\text { percentile }\end{array}$ & mean & $\begin{array}{c}25 \text { th } \\
\text { percentile }\end{array}$ & ESTAR & $\begin{array}{c}25 \text { th } \\
\text { percentile }\end{array}$ & mean & $\begin{array}{c}25 \text { th } \\
\text { percentile }\end{array}$ & Baseline & 25th percentile & $\mathrm{kWh} / \mathrm{yr}$ \\
\hline 0-10 ppm Inkjet & 10 & 9 & 6 & 2 & - & - & 1 & 1 & 44 & 21 & 23 \\
\hline 10-20 ppm Inkjet & 16 & 10 & 7 & 3 & - & - & 4 & 1 & 62 & 27 & 34 \\
\hline 20-30 ppm Inkjet & 13 & 13 & 6 & 4 & - & - & 2 & 0 & 49 & 32 & 16 \\
\hline $10-20 \mathrm{ppm}$ MFD & 17 & 14 & 11 & 9 & 7 & 6 & 6 & 6 & 73 & 63 & 10 \\
\hline 10-20 ppm BW Laser & 295 & 281 & 25 & 8 & 20 & 7 & 0 & 0 & 303 & 206 & 97 \\
\hline 20-30 ppm BW Laser & 786 & 727 & 43 & 31 & 30 & 15 & 0 & 0 & 663 & 540 & 123 \\
\hline 30-44 ppm BW Laser & 1125 & 1028 & 86 & 68 & 40 & 25 & 0 & 0 & 973 & 818 & 155 \\
\hline 0-10 ppm Color Laser & 491 & 447 & 74 & 27 & 35 & 23 & 0 & 0 & 565 & 408 & 157 \\
\hline 10-20 ppm Color Laser & 468 & 345 & 72 & 53 & 45 & 25 & 0 & 0 & 597 & 399 & 197 \\
\hline Notes: & & & & & & & & & & & \\
\hline 1. Only performed ce & tions & egories & hich & had data fo & ach mode & e (inkjets & only & lid not ha & sleep pov & setting in con & henu \\
\hline 2. For inkjet print only & levices, $\mathrm{w}$ & assumed th & following & & & & & & & & \\
\hline Active mode $=2.4$ hou & $\mathrm{s} /$ day, Re & dy mode $=6.6$ & hours/day & Off mode $=1$ & 5 hours pe & er day. & & & & & \\
\hline 3. For laser printers we & assumed & e following: & & & & & & & & & \\
\hline Active mode $=2.4$ hou & $\mathrm{s} /$ day, $\operatorname{Re}$ & dy mode $=6.2$ & hours/day & Sleep Mod & $=0.4 \mathrm{hrs} / \mathrm{d}$ & ay Off me & 15 hou & day. & & & \\
\hline 4. All printers assumed & to operate & 40 days/yr, & so assum & d $71 \%$ left o & n $24 \mathrm{hrs} / \mathrm{d}$ & & & & & & \\
\hline 5. Assumptions from & ebber et a & 2003 & & & & & & & & & \\
\hline 6. Usage patterns weig & ted by pri & ter stock b & resi & ial and & & & & & & & \\
\hline 7. Baseline case UEC & urrent & ERY S & fit & 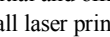 & $\mathrm{Fon}$ & & & & & & \\
\hline
\end{tabular}

\section{Observations on Sleep Mode}

During our testing, we made the following observations related to the sleep mode performance on models tested:

- The HP lj3330 all-in-one failed to enter sleep mode when set through control panel

- The HP PSC 2110 all-in-one failed to enter sleep mode when set through control panel

- Two of the color laser printers, the Tektronics 750 and Xerox 6200 did not enter sleep mode during the hour-long logging test, although both did when metered manually.

- When the sleep delay on the HP4550DN was set to "1 minute" it entered sleep mode in 52 seconds. The wake time on the unit was actually greater than one minute, so before the unit was able to fully wake up, it went back to sleep.

- The HP inkjet printer-based MFDs have a minimum sleep delay of one hour

- Tektronics 850 had an Intelligent Ready mode in addition to a Ready mode although the power consumption was no different.

\section{Information on Recovery Times}

During our testing, we recorded the recovery time from sleep-mode. As mentioned in the methodology, results are order-of-magnitude estimates. Although ENERGY STAR stipulates recovery times for certain products, the specification does not include a test procedure for measuring recovery times. In absence of this procedure, we simply measured recovery times based on our best judgment as to when the unit was fully awake and again able to fully perform its intended function. Because our procedure is not reproducible (when they unit was fully awake is based on interpretation), results should be applied with care. 
Our results show that in general units with a sleep power of greater than $25 \mathrm{~W}$ had longer recovery times (Figure 9). Color laser printers tended to have long recovery times (these were also high sleep-mode power units). However, both the HP4600 and the Xerox 6200 had recovery times that were brief enough to appear instantaneous (these were also the newest color laser printers metered). We also found a large range in the distribution of recovery times for inkjets from $1 \mathrm{sec}$ to $24 \mathrm{sec}$ even though sleep power for these devices was low (less than 15 watts). For monochrome laser printers, we found that models with high speeds (30-ppm to $+44-\mathrm{ppm})$ and high power consumption in sleep-mode (these also tended to be the high speed bins) also tended to have the highest recovery times from sleep.

Figure 9: Recovery Times by Printer Type and Print Speed

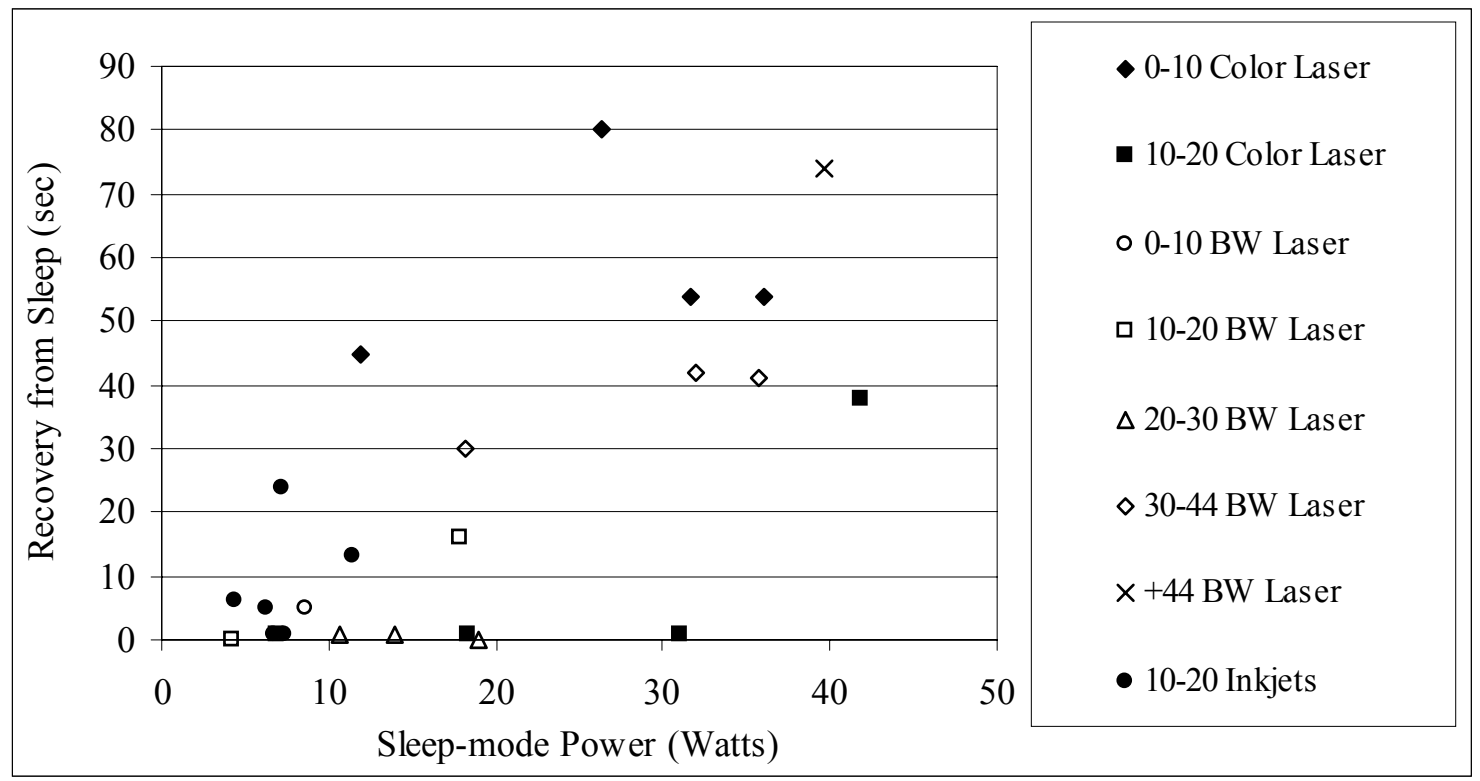

Comparison of Printer Data to Manufacturer Data

Below are comparisons between data collected by LBNL and manufacturer data. We have shaded models in gray (bold) where LBNL and manufacturer test data differed by greater then $+25 \%$. Measurements for models shaded in blue (italic) differed by greater than $-25 \%$. The index column on the far right of the table shows the ratio of LBNL test data to manufacturer reported values. Data for the manufacturers are from either the updated STAR database or from information published on the manufacturer's website. Sources for each individual product are listed below (Tables 4 \& 5). 
Table 4: Comparison of Fax Testing Data

\begin{tabular}{|l|l|c|l|l|c|}
\hline Manufacturer & Product & Ready (W)/LBNL & Standby (W)/Manuf & Source & Index \\
\hline Panasonic & KX-FHD351 & 3 & $3.6-4.0$ & Current STAR & 0.83 \\
\hline Brother & Fax1800c & 6 & $<7 \mathrm{~W}$ & Product Manual & 0.86 \\
\hline Sharp & UX-P100 & 3 & 3.45 & Current STAR & 0.87 \\
\hline Panasonic & KX-KHD331 & 3 & $3.0-3.3$ & Current STAR & 1 \\
\hline Brother & Fax775 & 4 & $<5 \mathrm{~W}$ & Product Manual & 1 \\
\hline Brother & Fax 2800 & 8 & $<10 \mathrm{~W}$ & Product Manual & 1 \\
\hline Brother & Fax 1270e & 4 & $<4 \mathrm{~W}$ & Product Manual & 1 \\
\hline Brother & Fax 4100 & 7 & $<10 \mathrm{~W}$ & Product Manual & 1 \\
\hline Hewlett Packard & HP Fax 1020 & 7 & Not Available & NA & - \\
\hline Sharp & UX-B700 & 5 & Not Available & NA & - \\
\hline
\end{tabular}

Notes:

1. Modal value is reported.

2. Evaluated differences between LBNL and manufacturer reported measurements on a $+-25 \%$ range. Products with differences greater than $25 \%$ are shaded gray with bold font. Products with differences greater than $-25 \%$ shaded in blue with italic font.

3. If product is reported as $<\mathrm{X}$ by a manufacturer: if product was metered at a level less than, we assumed an index value of 1 .

4. Index represents the ratio between LBNL measurement and the manufacturer reported value.

\section{Table 5: Comparison of Printer Testing Data}

\begin{tabular}{|c|c|c|c|c|c|c|c|}
\hline \multirow[b]{2}{*}{ Manufacturer } & \multirow[b]{2}{*}{ Product } & \multicolumn{2}{|c|}{ LBNL } & \multicolumn{3}{|c|}{ Manufacturer } & \multirow[t]{2}{*}{ Index } \\
\hline & & Ready (W) & Sleep $(\mathbf{W})$ & Ready (W) & Sleep (W) & Source & \\
\hline Hewlett-Packard & HP Deskjet 3420 & 3 & NA & 8 & 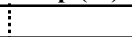 & current STAR & 0.38 \\
\hline Hewlett-Packard & HP Deskjet 845C & 2 & NA & 4 & $:$ & current STAR & 0.48 \\
\hline Hewlett-Packard & HP Deskjet 3820 & 2 & NA & 4 & 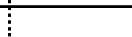 & current STAR & 0.53 \\
\hline Hewlett Packard & $\begin{array}{l}\text { HP Laserjet } 2500 \text { Color } \\
\text { Printer }\end{array}$ & 19 & NA & 31 & 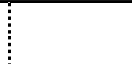 & current STAR & 0.62 \\
\hline Lexmark & Lexmark Z23 & 3 & NA & 4 & 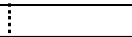 & current STAR & 0.65 \\
\hline Hewlett-Packard & HP Deskjet 5550 & 3 & NA & 4 & 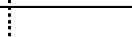 & current STAR & 0.73 \\
\hline Hewlett Packard & HP Laserjet 1200se & 4 & NA & 6 & 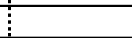 & current STAR & 0.73 \\
\hline Hewlett Packard & HPlj 3330 & 11 & NA & 14 & & Product Literature & 0.75 \\
\hline Lexmark & Lexmark Z55se & 3 & NA & 4 & & current STAR & 0.78 \\
\hline Brother & Brother HL-1850 Laser & 8 & 7 & & 9 & & 0.78 \\
\hline Hewlett Packard & $\begin{array}{l}\text { HP Laserjet } 3300 \\
\text { Printer/Copier/Scanner }\end{array}$ & 11 & 8 & 14 & & Product Literature & 0.79 \\
\hline Epson & Epson Stylus C62 & 3 & NA & 4 & & current STAR & 0.80 \\
\hline Lexmark & Lexmark Photojet print Z65P & 5 & NA & 6 & & current STAR & 0.82 \\
\hline Epson & Epson Stylus C82 & 3 & NA & 3.5 & & current STAR & 0.83 \\
\hline Brother & $\begin{array}{l}\text { Brother HL-5040 Personal } \\
\text { Laser }\end{array}$ & 6 & 4 & & 5 & & 0.84 \\
\hline Hewlett Packard & $2200 \mathrm{dn}$ & 10 & NA & 12 & 8 & current STAR & 0.85 \\
\hline Hewlett Packard & HP Laserjet 1000 & 6 & NA & 7 & $\div$ & current STAR & 0.89 \\
\hline Hewlett Packard & HP Laserjet 4200 & 19 & 18 & & 20 & current STAR & 0.91 \\
\hline Brother & Brother MFC 3100C & 6 & NA & $<7 \mathrm{~W}$ & $\dot{\vdots}$ & Product Literature & 1.00 \\
\hline Brother & $\begin{array}{l}\text { Brother MFC } 4800 \text { Laser All- } \\
\text { in-one }\end{array}$ & 9 & 9 & & $<10 \mathrm{~W}$ & & 1.00 \\
\hline Brother & $\begin{array}{l}\text { Brother MFC 5100C Inkjet } \\
\text { All-in-one }\end{array}$ & 13 & NA & $<13.5$ & & Product Literature & 1.00 \\
\hline Epson & Epson Stylus C42UX & 3 & NA & 3 & 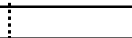 & current STAR & 1.00 \\
\hline Hewlett Packard & HP9000DN & 230 & 40 & $90-100$ & $35-45$ & Product Literature & 1.00 \\
\hline
\end{tabular}


Table 5: Comparison of Printer Data (continued)

\begin{tabular}{|c|c|c|c|c|c|c|c|}
\hline & \multirow[b]{2}{*}{ Product } & \multicolumn{2}{|c|}{ LBNL } & \multicolumn{3}{|c|}{ Manufacturer } & \multirow[t]{2}{*}{ Index } \\
\hline & & Ready (W) & Sleep (W) & Ready (W) & Sleep (W) & Source & \\
\hline Hewlett Packard & HP 4550DN & 30 & 36 & & 35 & current STAR & 1.03 \\
\hline Hewlett Packard & HP 8150 & 117 & 36 & & 31 & current STAR & 1.15 \\
\hline Hewlett Packard & HP 4550 & 137 & 32 & & 27 & current STAR & 1.17 \\
\hline Hewlett-Packard & HP Deskjet 6122 & 2 & NA & 2 & & Product Literature & 1.20 \\
\hline Hewlett-Packard & $\begin{array}{l}\text { HP Business Inkjet (1-5 users) } \\
2230\end{array}$ & 10 & NA & 8 & & Product Literature & 1.24 \\
\hline Canon & Canon i320 Bubblejet & 1 & NA & 1 & & current STAR & 1.40 \\
\hline Epson & Epson Stylus Photo 820 & 7 & NA & 4 & 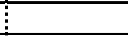 & Product Literature & 1.68 \\
\hline Canon & Canon i550 Bubblejet & 3 & NA & 1 & & current STAR & 3.10 \\
\hline Epson & $4000 \mathrm{~N}$ & 17 & 18 & & & & \\
\hline Hewlett Packard & $4100 \mathrm{dn}$ & 19 & 19 & & & & \\
\hline Epson & Epson Stylus CX3200 & 13 & NA & & & & \\
\hline Epson & Epson Stylus CX5200 & 10 & NA & & & & \\
\hline Epson & Epson Stylus Photo 785 EPX & 12 & NA & & & & \\
\hline Hewlett Packard & HP 2250TN & 15 & NA & & & & \\
\hline Hewlett-Packard & HP 4600 & 31 & 31 & & & & \\
\hline Hewlett-Packard & HP 8100 & 121 & 32 & & & & \\
\hline Hewlett Packard & HP Officejet 6110 & 6 & 6 & & & & \\
\hline Hewlett Packard & HP Officejet d135 & 18 & 12 & & & & \\
\hline Hewlett-Packard & HP Officejet K80 & 9 & 7 & & & & \\
\hline Hewlett-Packard & HP Photosmart 7150 & 3 & NA & 40 Max & & Product Literature & \\
\hline Hewlett Packard & HP Photosmart 7350 & 5 & NA & $45 \operatorname{Max}$ & & Product Literature & \\
\hline Hewlett Packard & HP Photosmart 7550 & 6 & NA & $45 \operatorname{Max}$ & & Product Literature & \\
\hline Hewlett Packard & HP PSC 2110 & 11 & NA & & & & \\
\hline Hewlett Packard & HP PSC 2210 & 11 & 8 & & & & \\
\hline Hewlett Packard & HP PSC 750 & 7 & 5 & & & & \\
\hline Lexmark & Lexmark T520 & 83 & 11 & & & & \\
\hline Lexmark & Lexmark T620 & 67 & 14 & & & & \\
\hline Lexmark & Lexmark X83 & 12 & 7 & & & & \\
\hline Lexmark & Lexmark Z45 SE Inkjet & 4 & NA & & & & \\
\hline Minolta & $\begin{array}{l}\text { Minolta QMS Magicolor } \\
\text { 2300 Desktop Laser }\end{array}$ & 20 & 12 & & & & \\
\hline Tecktronics & Tecktronics 850 & 164 & NA & & & & \\
\hline Tecktronics & Tektronics 750 & 31 & 26 & & 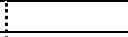 & & \\
\hline Xerox & Xerox 1235 & 110 & 42 & & 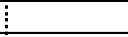 & & \\
\hline Xerox & Xerox 6200 & 75 & 18 & & $i$ & & \\
\hline
\end{tabular}

Notes:

1. Modal value is reported.

2. Evaluated differences between LBNL and manufacturer reported measurements on a $+-25 \%$ range. Products with differences greater than $25 \%$ are shaded gray with bold font. Products with differences greater than $-25 \%$ shaded in blue with italic font.

3. If product is reported as $<X$ by a manufacturer: if product was metered at a level less than, we assumed an index value of 1 .

4. Index represents the ratio between LBNL measurement and the manufacturer reported value.

In comparing the LBNL test data to the manufacturer's test data for printers and fax machines, we found some inconsistencies in the data. Some possible explanations are variations between models, that manufacturer's often report worst-case scenarios (i.e. manufacturers often meter multiple models and then submit the worst test result), and actual discrepancies between the two measurements.

\section{Results for Photocopiers}

We metered 19 copiers at Office Max, Office Depot, LBNL and City of Berkeley. Products represented 5 manufacturers. There were three technologies represented; inkjet, electrostatic transfer and laser. We tested products in all three speed bins for standard 
sized copiers; no large format copiers were metered. All copiers metered appeared to have sleep modes but we found that several devices did not enter one or more low power modes when set to enter such mode. Because of the relatively small number of devices we did not attempt a quartile analysis for copiers. Like the large laser printers, the copiers with laser engines displayed power cycling in most modes.

Table 6 shows results for copiers. All but 5 of our sample had some power consumption while off. For most units the off power consumption was below 5 watts, but one unit had a very high "spike" of over 650 watts in its off power usage while off (Kyocera 6330, this model was not labeled ENERGY STAR).

Table 6: Summary Results for Photocopiers

\begin{tabular}{|c|c|c|c|c|c|}
\hline & Off $(W)$ & Ready (W) & Sleep (W) & $\begin{array}{c}\text { Recover from } \\
\text { Sleep (sec) }\end{array}$ & $\begin{array}{c}\text { Recover from } \\
\text { Off (sec) }\end{array}$ \\
\hline \begin{tabular}{|l|} 
All copiers \\
Count \\
Min \\
Max \\
Average \\
\end{tabular} & $\begin{array}{c}19 \\
0 \\
696 \\
3 \\
\end{array}$ & $\begin{array}{c}19 \\
3 \\
1341 \\
116 \\
\end{array}$ & $\begin{array}{c}19 \\
0 \\
1132 \\
64 \\
\end{array}$ & $\begin{array}{c}16 \\
1 \\
129 \\
45 \\
\end{array}$ & $\begin{array}{c}18 \\
1 \\
224 \\
88 \\
\end{array}$ \\
\hline $\begin{array}{l}\text { Low-speed standard-sized } \\
\text { copiers (0-20 CPM) } \\
\text { Count } \\
\text { Min } \\
\text { Max } \\
\text { Average } \\
\end{array}$ & $\begin{array}{l}9 \\
0 \\
4 \\
1 \\
\end{array}$ & $\begin{array}{c}9 \\
7 \\
337 \\
20 \\
\end{array}$ & $\begin{array}{c}9 \\
1 \\
26 \\
6 \\
\end{array}$ & $\begin{array}{c}8 \\
5 \\
55 \\
37 \\
\end{array}$ & $\begin{array}{c}9 \\
1 \\
77 \\
36 \\
\end{array}$ \\
\hline $\begin{array}{l}\text { Mid-speed standard-sized } \\
\text { copiers (20-44 CPM) } \\
\text { Count } \\
\text { Min } \\
\text { Max } \\
\text { Average }\end{array}$ & $\begin{array}{l}1 \\
0 \\
4 \\
1\end{array}$ & $\begin{array}{c}1 \\
44 \\
1220 \\
180\end{array}$ & $\begin{array}{c}1 \\
33 \\
1005 \\
97\end{array}$ & $\begin{array}{l}1 \\
1 \\
1 \\
1\end{array}$ & $\begin{array}{c}1 \\
36 \\
36 \\
36\end{array}$ \\
\hline $\begin{array}{l}\text { High-speed standard-sized } \\
\text { copiers (>44 CPM) } \\
\text { Count } \\
\text { Min } \\
\text { Max } \\
\text { Average }\end{array}$ & $\begin{array}{c}7 \\
0 \\
696 \\
6\end{array}$ & $\begin{array}{c}7 \\
3 \\
1341 \\
208\end{array}$ & $\begin{array}{c}7 \\
0 \\
1132 \\
121\end{array}$ & $\begin{array}{c}7 \\
5 \\
129 \\
64\end{array}$ & $\begin{array}{c}8 \\
70 \\
224 \\
153\end{array}$ \\
\hline
\end{tabular}

Notes:

No quartile analysis performed due to limitations on sample size.

Copiers in the Low-speed category had the lowest power consumptions. In our sample the medium-speed copiers had higher ready power consumption than those in the highspeed bin. This finding seems unlikely to be general, and is probably an artifact of this particular sample (Figure 10 $)^{5}$.

\footnotetext{
${ }^{5}$ Our hours of usage estimates are taken from Webber et al., 2003. These estimates include a value for "on" time, which encompasses both active and ready mode. Maximum on time per day is 10 hours in an office setting. If the copy usage of the copier was 0 hours per day, the ready time would=10 hours/day.
} 
Figure 10: Results for Photocopier by Copy Speed

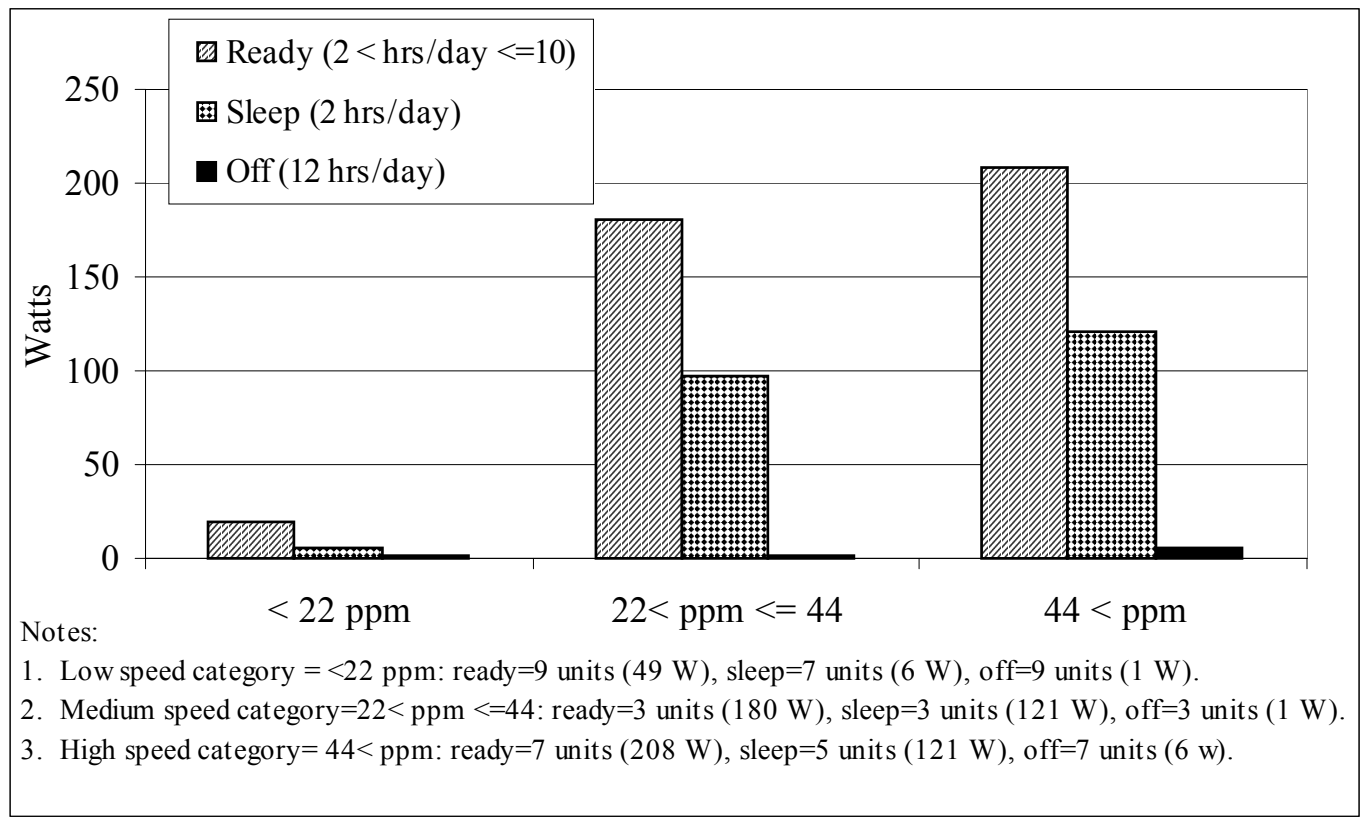

\section{Figure 11: Results for Photocopiers by Copy Engine}

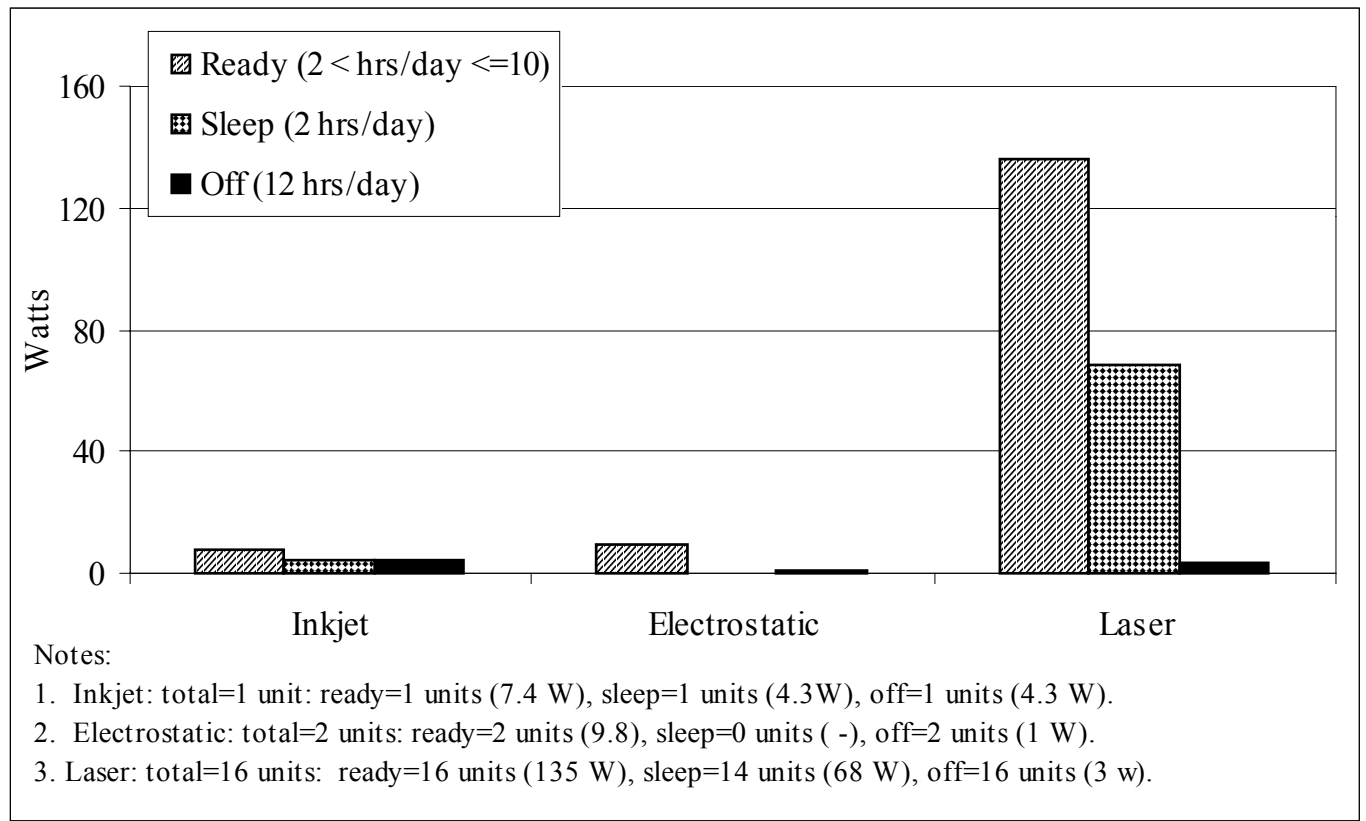


Figure 12: Results for Low Speed Photocopiers

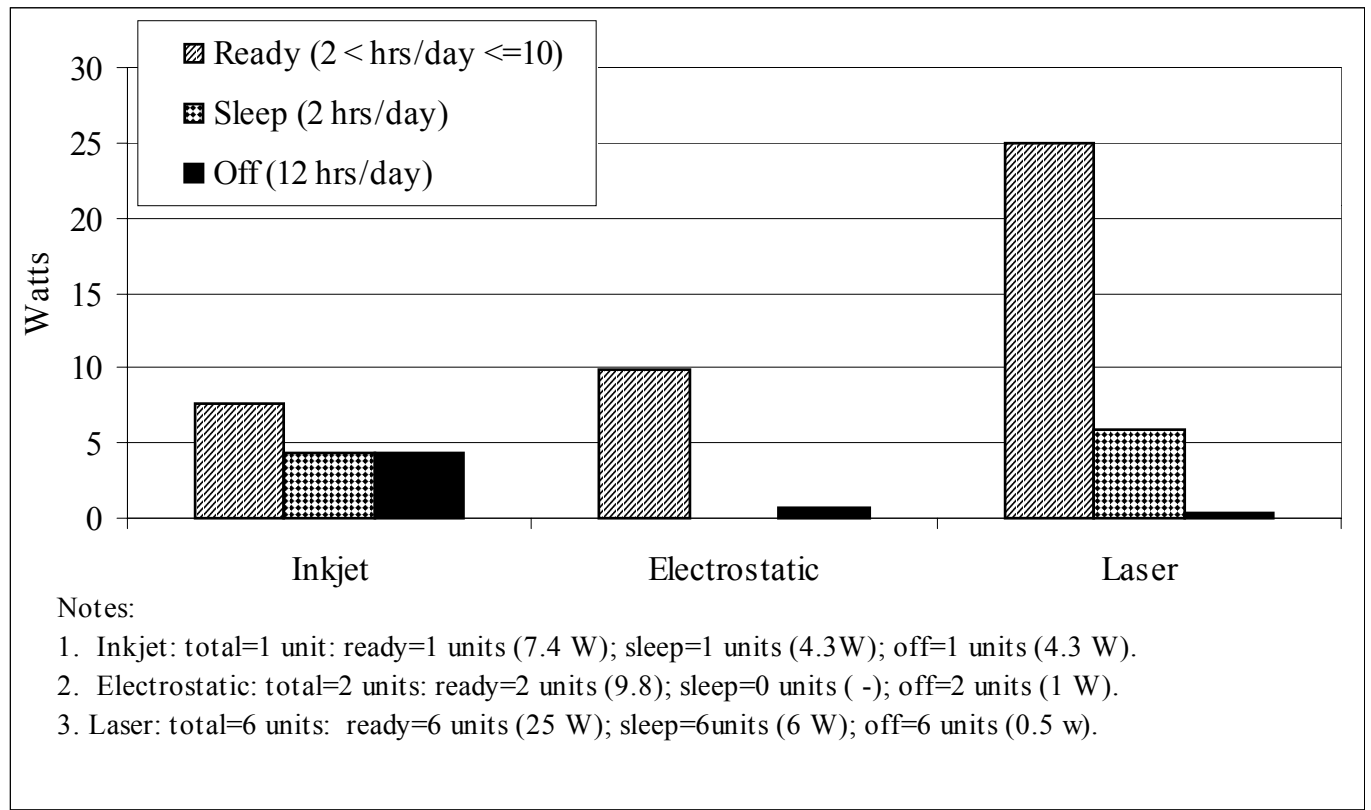

Power consumption also differed by technology type as shown in Figure 11, with the inkjet device having the lowest power consumption, followed by the two electrostatic transfer devices, with laser machines having the highest consumption.

Because all of the medium- and high-speed copiers use laser technology, a comparison was made among the low speed machines. This comparison is shown in Figure 12.

While the difference was less pronounced when the faster machines were excluded, even among the low speed group the laser copiers still had higher ready power consumption. Although they had higher ready consumption the laser copiers had lower power consumption when off.

We compared the measured power consumption of our sample of copiers to the requirements of the current specification. Although only about half of the copiers in our sample were listed in the ENERGY STAR database, we found that the majority of models not only meet the current specification level, but also consumed substantially less power than the current criteria. Of our 15 tested units where we had low power measurements only one did not meet the specification. Similarly of the 19 units only one failed to meet the specification for off power (Table 7). 
Table 7: Comparison of Metered Data to ENERGY STAR Requirements

\begin{tabular}{|c|c|c|c|c|c|c|c|}
\hline Speed & Product & $\begin{array}{c}\mathbf{E}^{*} \text { Low } \\
\text { Power }(\mathbf{W})\end{array}$ & $\begin{array}{l}\text { Actual low } \\
\text { Power (W) }\end{array}$ & Qualify? & $E^{*}$ Off $(W)$ & $\begin{array}{l}\text { tual c } \\
\text { (W) }\end{array}$ & Qualify? \\
\hline \multirow{9}{*}{ Low (0-20 CPM) } & Canon 428 Color & 20 & NA & NA & 5 & 1 & Yes \\
\hline & Canon 940 & 55 & NA & NA & 5 & 1 & Yes \\
\hline & HP 310 Digital Inkjet & 51 & 4 & Yes & 5 & 4 & Yes \\
\hline & Canon Imageclass D660 & 55 & 1 & Yes & 5 & 1 & Yes \\
\hline & Canon Imagiclass D680 & 55 & 1 & Yes & 5 & 1 & Yes \\
\hline & Sharp AL-1530CS & 63 & 3 & Yes & 5 & 0 & Yes \\
\hline & Sharp AL-1551CS & 63 & 3 & Yes & 5 & 0 & Yes \\
\hline & Sharp AL-1540C & 63 & 3 & Yes & 5 & 0 & Yes \\
\hline & Kyocera 1810 & 74 & 23 & Yes & 5 & 0 & Yes \\
\hline \multirow[t]{3}{*}{ Medium (20-44 CPM) } & HP 8550 & 97 & 71 & Yes & 15 & 1 & Yes \\
\hline & Kyocera 3530 & 140 & 123 & Yes & 15 & 2 & Yes \\
\hline & Kyocera 3130 & 124 & 105 & Yes & 20 & 2 & Yes \\
\hline \multirow[t]{7}{*}{ High ( $>44$ CPM) } & Kyocera 4530 & 178 & 79 & Yes & 20 & 4 & Yes \\
\hline & Kyocera 4530(MFD) & 178 & 97 & Yes & 20 & 3 & Yes \\
\hline & Canon 6050 & 198 & Not obtained & NA & 20 & 0 & Yes \\
\hline & Kyocera 5530 & 217 & 112 & Yes & 20 & 3 & Yes \\
\hline & Kyocera 6230 & 217 & 249 & No & 20 & 0 & Yes \\
\hline & Xerox 555 & 217 & Not obtained & NA & 20 & 3 & Yes \\
\hline & Kyocera 6330 & 248 & 83 & Yes & 20 & 36 & No \\
\hline
\end{tabular}

The two Kyocera Model 4530 copiers we tested behaved somewhat differently. The device configured as a copier had somewhat lower power consumptions. The device configured as a MFD had higher active power user ( $871 \mathrm{~W}$ for the copier, $800 \mathrm{~W}$ for the MFD), and Off (3.5 W for the copier, $2.8 \mathrm{~W}$ for the MFD), but the copier had lower consumption in ready mode (191 W for the copier, $212 \mathrm{~W}$ for the MFD), and sleep (79 $\mathrm{W}, 97 \mathrm{~W}$ ) modes. The auto off mode did not function for the MFD.

In contrast to power consumption where compliance with the ENERGY STAR specification was high, the copiers in our sample did not perform well compared to the ENERGY STAR specification for recovery times ${ }^{6}$. The low- and high-speed bins do not have a specific requirement so calculating a percentage of compliance would be misleading, but of the 14 copiers for which we obtained recovery from sleep times only four recovered from sleep in less than thirty seconds. For one of these three, the Kyocera 4530 configured as MFD widely different recovery times were noted for recovery from manual and automatic low power modes (Table 8).

Recovery times were not obtained for five units: the Canon Model 428, Canon Model 940 which did not have sleep modes, the Canon 6050 and the Kyocera 1810 because of restrictions placed by the operator, and the Xerox 555 due to the unit not entering sleep.

\footnotetext{
${ }^{6}$ Our methodology limited us to determining recovery by visually judging the power status light to determine when the unit was ready to print. It is possible that this conservatively estimates our recovery time and that actual time to print (recovery time to a user) is longer.
} 
Table 8: Comparison of Observed Recovery Times to ENERGY STAR Requirements

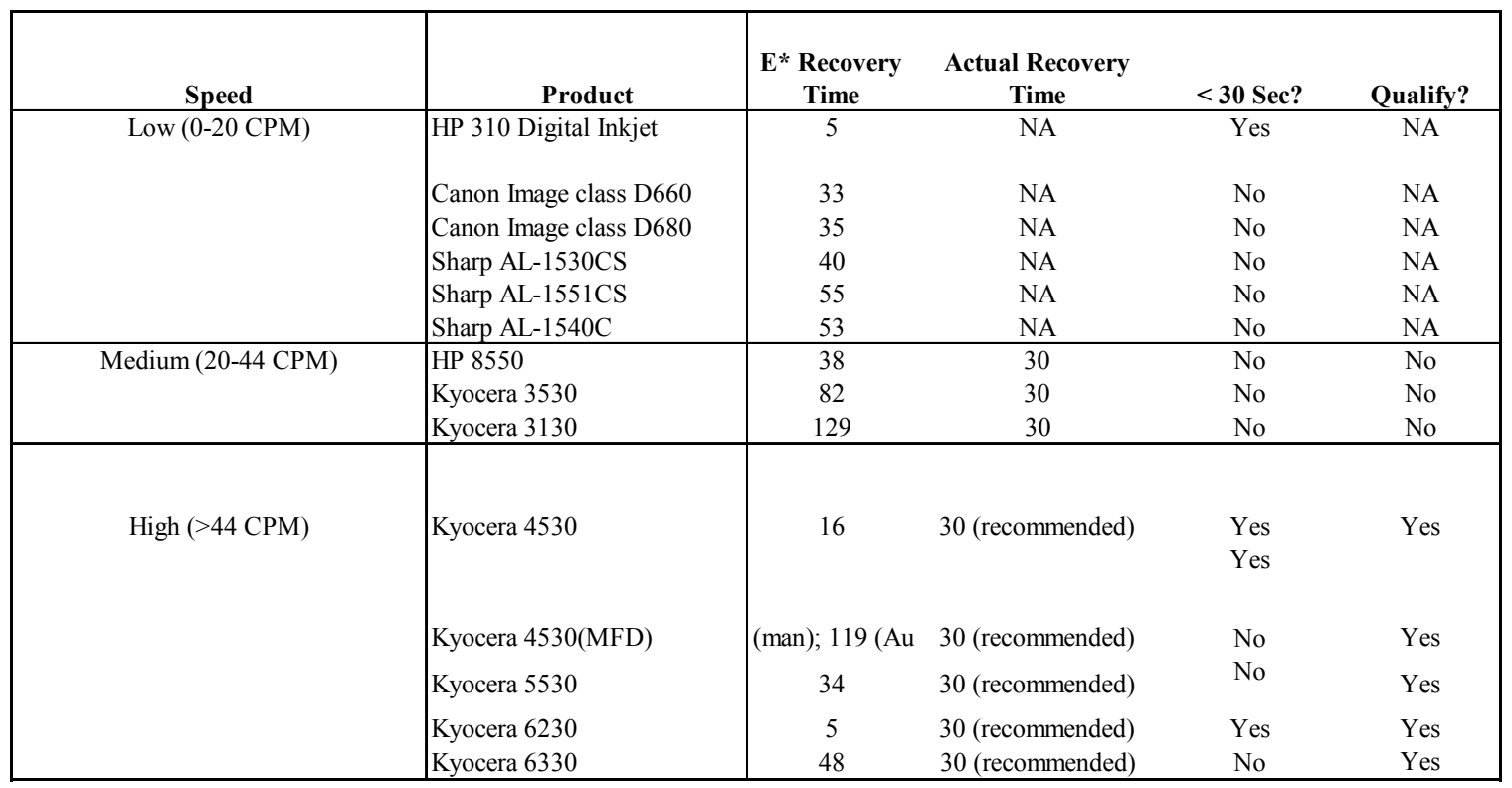

\section{Observations on Sleep Mode}

There is no sleep data for four of the tested copiers; data was not obtained for one machine due to restrictions created by the machine's user.

- The two Electrostatic transfer type copiers did not have sleep modes.

- The Kyocera Model 4530 configured networked MFD did not enter sleep mode automatically.

- The Canon 940 is not listed as having an auto-off feature, on the manufacturer's website.

- The Xerox 555 did not enter either sleep-mode or auto-off.

- The Kyocera/Mita 6230 did not appear to have user configurable options for sleep or auto off delay; we examined both the device menus, and the printed manual. This device did have a manual 'energy saver' mode and a weekly timer which could turn the device off.

\section{Comparisons of Photocopier Data to Manufacturer's Data}

In comparing our metered data to manufacturer reported data, we found substantial differences, especially for the Kyocera models (Table 9). ENERGY STAR asks manufacturers to report sleep power consumption in its product reporting form, which is defined as the lowest power mode achieved without the unit turning off. The differences between our estimates and the manufacturers are so extreme that it seems likely that the manufacturer, in this case, may not be reporting sleep at all, but rather off mode power. Possible discrepancies in product reporting are of particular concern since EPA uses the STAR database in helping set future ENERGY STAR specifications as well as evaluate program achievements. 
Table 9: Comparison of Copier Metered Data to Manufacturer Data

\begin{tabular}{|c|c|c|c|c|c|c|c|}
\hline \multirow[b]{2}{*}{ Manufacturer } & \multirow[b]{2}{*}{ Product } & \multicolumn{2}{|c|}{ LBNL } & \multicolumn{3}{|c|}{ Manufacturer } & \multirow[t]{2}{*}{ Index } \\
\hline & & Ready (W) & Sleep $(W)$ & Ready (W) & Sleep $(W)$ & Source & \\
\hline Canon & Canon Imageclass D680 & 14 & 1 & NA & 1.7 & \begin{tabular}{|l} 
STAR \\
Database
\end{tabular} & 0.71 \\
\hline Canon & Canon Imageclass D660 & 13 & 1 & NA & 1.5 & \begin{tabular}{|l} 
STAR \\
Database
\end{tabular} & 0.73 \\
\hline Sharp & Sharp AL-1540C & 17 & 3 & 15 & 3.3 & \begin{tabular}{|l|} 
STAR \\
Database
\end{tabular} & 0.94 \\
\hline Sharp & Sharp AL-1530CS & 17 & 3 & 15 & 3.3 & $\begin{array}{l}\text { STAR } \\
\text { Database } \\
\end{array}$ & 0.97 \\
\hline Sharp & Sharp AL-1551CS & 17 & 3 & 42 & 3 & $\begin{array}{l}\text { STAR } \\
\text { Database }\end{array}$ & 1.00 \\
\hline Kyocera/Mita & Kyocera 6330 & 146 & 83 & 198 & 11 & $\begin{array}{l}\text { STAR } \\
\text { Database } \\
\end{array}$ & 7.55 \\
\hline Kyocera/Mita & Kyocera 3130 & 233 & 105 & 98 & 3 & $\begin{array}{l}\text { STAR } \\
\text { Database }\end{array}$ & 35.10 \\
\hline Kyocera/Mita & Kyocera 4530 & 191 & 79 & 145 & 1 & $\begin{array}{l}\text { STAR } \\
\text { Database }\end{array}$ & 79.40 \\
\hline Kyocera/Mita & Kyocera 4530 (2nd uint) & 212 & 97 & 145 & 1 & $\begin{array}{l}\text { STAR } \\
\text { Database } \\
\end{array}$ & 97.20 \\
\hline Kyocera/Mita & Kyocera 5530 & 192 & 112 & 131 & 1 & \begin{tabular}{|l|} 
STAR \\
Database \\
\end{tabular} & 112.10 \\
\hline Canon & Canon 428 Color & 7 & Not obtained & & & & \\
\hline Canon & $\begin{array}{l}\text { Canon Personal } 940 \text { Copier } \\
\text { (BW) }\end{array}$ & 13 & Not obtained & & & & \\
\hline Hewlett-Packard & $\begin{array}{l}\text { HP } 310 \text { Digital Inkjet Color } \\
\text { Copier }\end{array}$ & 8 & 4 & & & & \\
\hline Kyocera/Mita & Kyocera 1810 & 72 & 23 & & & & \\
\hline Kyocera/Mita & Kyocera 3530 & 124 & 123 & & & & \\
\hline Kyocera/Mita & Kyocera 6230 & 255 & 249 & & & & \\
\hline Canon & Canon 6050 & 321 & Not obtained & & & & \\
\hline Xerox & Xerox 555 & 132 & Not obtained & 145 & 65 & & \\
\hline Hewlett-Packard & HP 8550 & 237 & 71 & & & & \\
\hline
\end{tabular}

Notes:

1. Modal value is reported.

2. Evaluated differences between LBNL and manufacturer reported measurements on a $+-25 \%$ range. Products with differences greater than $25 \%$ are shaded gray with bold font. Products with differences greater than $-25 \%$ shaded in blue with italic font.

3. If product is reported as $<\mathrm{X}$ by a manufacturer: if product was metered at a level less than, we assumed an index value of 1 .

4. Index represents the ratio between LBNL measurement and the manufacturer reported value.

\section{Manufacturer Labeling Practices}

We evaluated manufacturer-labeling practices for printers and faxes that were metered manually in stores. We recorded whether or not a product was indicated to be ENERGY STAR based on one of the following: label visible on product in store (we noted only if products were labeled on the unit itself - i.e. we did not check product boxes for labels), the product was easily identified as ENERGY STAR on the manufacturer's website, or the product was listed in the STAR database or in the product literature. If the product was not apparently ENERGY STAR, we recorded it as "not indicated." All products that are not indicated are reported as not labeled. The results of our metering efforts are summarized in Tables 10 \& 11. 
We found that only one quarter of all printer products were actually labeled in the store (over $90 \%$ of all printers and faxes are ENERGY STAR). We found a slightly higher percentage of fax machines labeled $(36 \%)$. Of the products labeled, we found very few color or black and white-ENERGY STAR stickers fixed to the front of imaging products. Instead, most printers and faxes that were labeled had a black and white label on the nameplate (typically on the back or bottom of the product). A few labels were embedded into the bottom or back of the device. Currently, mandatory product labeling is not a requirement of the imaging specification; however, increased visual presence of the label as a both a marketing and consumer identification tool would be a program benefit.

\section{Table 10: Summary of Fax Labeling in Stores}

\begin{tabular}{|l|cc|c|}
\hline Manufacturer & ENERGY STAR $^{\mathbf{1}}$ & LABELED $^{\mathbf{2}}$ & NOT INDICATED \\
\hline Brother & 2 & 0 & 3 \\
Hewlett Packard & 1 & 1 & 0 \\
Panasonic & 3 & 3 & 0 \\
Sharp & 0 & 0 & 2 \\
\hline TOTALS & 6 & 4 & 5 \\
\hline \% of Total Sample $=$ & $55 \%$ & $36 \%$ & $45 \%$ \\
\hline
\end{tabular}

1. We recorded products that we were able to identify as ENERGY STAR from either the label being on the object or through the manufacturer's website or the product brochure.

2. Labeled products only reflect actual product labeling. We did not look at product shipping materials such as boxes for the label.

Table 11: Summary of Printer Labeling in Stores

\begin{tabular}{|l|cc|c|}
\hline Manufacturer & ENERGY STAR $^{\mathbf{1}}$ & LABELED $^{\mathbf{2}}$ & NOT INDICATED \\
\hline Hewlett Packard & 19 & 9 & 12 \\
Lexmark & 4 & 4 & 3 \\
Epson & 1 & 0 & 6 \\
Brother & 3 & 0 & 2 \\
Canon & 2 & 0 & 0 \\
Tektronics & 0 & 0 & 2 \\
Minolta & 1 & 1 & 0 \\
Xerox & 1 & 0 & 1 \\
\hline TOTALS & 31 & 14 & 26 \\
\hline \% of Total Sample $=$ & $54 \%$ & $25 \%$ & $46 \%$ \\
\hline
\end{tabular}

1. We recorded products that we were able to identify as ENERGY STAR from either the label being on the object or through the manufacturer's website or the product brochure.

2. Labeled products only reflect actual product labeling. We did not look at product shipping materials such as boxes for the label.

\section{Conclusions}

Our sample shows that over $90 \%$ of the current imaging market complies with the current ENERGY STAR specifications. Based on these findings, the current specification needs to be tightened. 
We found that our metered data for printers and copiers varied most substantially by print engine. There may exist a possibility of achieving additional program savings by structuring the specification by print engine. We found the inkjet printers consume substantially less power in active and low power modes than laser technology. On average, they consume more power in off mode due to the use of external power supplies (EPA can achieve savings by requiring the use of efficient power supplies). These power estimates translate into substantially different annual energy consumption estimates as well as potential energy savings.

We also found that unlike laser printers that vary in active, standby, and sleep-mode power across the greater than 20-ppm speed-bin, inkjet printers only vary by 2-4 watts across the 0-30 ppm speed bins (also favoring a separate specification).

We analyzed the top quartile of energy efficient products (typically where ENERGY STAR sets the specification) for faxes and printers. For faxes, we found that the top quartile of products consumed 4 watts (substantially lower than the current $10 \mathrm{~W}$ specification). For printers, we found similar results, with the top quartile of products consuming substantially less than current levels across speed bins greater than 10-ppm (Appendix D).

For copiers, we compared individual units to their respective ENERGY STAR low power criteria and found that many were substantially lower than the requirements. However, very few models recovered from sleep within the necessary time period.

In conducting this study, we found that although ENERGY STAR specifies recovery time limits for certain products, there is currently no test procedure for measuring recovery times. Our method was limited to interpreting when a unit recovered from sleep by judging the power status light, which may or may not be the same as when a unit is able to make its first copy/print. Our method was further limited because we did not standardize for ensuring a unit returned to ambient temperature before recording recovery time. As such, our results should be viewed as order of magnitude estimates. These difficulties suggest the need for an agreed on test procedure for measuring recovery times.

We compared our metered data to manufacturer reported data compiled by ENERGY STAR through the product reporting process. We found serious discrepancies in the Kyocera copier data. The differences between the data are so extreme that it appears likely that the manufacturer is reporting off-mode data. This finding again raises the concern of manufacturer's accuracy in self-reporting since the data is used to set specifications and evaluate the program. We also noted in the product reporting manufacturer's use of the qualification " $<$ X Watts". Because this can potentially capture such a wide range in values, it really provides very limited useful data and moving forward, we suggest that manufacturer's report simply a value $\mathrm{X}$. 
We found only a small percentage of ENERGY STAR products labeled on the unit itself. Products that were labeled, typically had the label on the nameplate or back of the unit. This raises the issue that when consumers enter the store, they do not see the label on imaging equipment. In revising the specification, this is one possible area that can be targeted since as the percentage of qualifying market decreases (with the specification revision), having the ENERGY STAR logo on the product will make it easier for consumers to identify a product in the store.

\section{Acknowledgements}

We would like to thanks the following organizations for their cooperation in our metering efforts: Office Max, Office Depot, and City of Berkeley. We also thank Jeff Harris (LBNL) and Hans-Paul Sierius (NOVEM) for reviewing this paper.

\section{References}

Kawamoto, Kaoru, J. Koomey, M. Ting, B. Nordman, R. Brown, M. Piette, A. Meier. 2001. Electricity Used by Office Equipment and Network Equipment in the U.S.: Detailed Report and Appendices. LBNL-45917. Lawrence Berkeley National Laboratory, Berkeley CA. February.

McWhinney, M., A. Fanara, R. Clark, C. Hershberg, R. Schmeltz, J. Roberson. 2003. ENERGY STAR Product Development Framework: Using Data and Analysis to Make Program Decisions. LBNL-48581. Lawrence Berkeley National Laboratory, Berkeley CA.

Nordman, Bruce, A. Meier, and M Piette. 2000. PC and Monitor Night Status: Power Management Enabling and Manual Turn-Off. LBNL-46099. Lawrence Berkeley National Laboratory, Berkeley CA.

Nordman, Bruce, M. Piette, and K Kinney. 1996. Measured Energy Savings and Performance Power-Managed Personal Computers and Monitors. LBNL-38057. Lawrence Berkeley National Laboratory, Berkeley CA.

Roberson, Judy, G. Homan, A. Mahajan, B. Nordman, C. Webber, R. Brown, M. McWhinney, J. Koomey. 2002. Energy Use and Power Levels in New Monitors and Personal Computers. LBNL-48581. Lawrence Berkeley National Laboratory, Berkeley CA. July.

US EPA. 1997. Multifunction Device Memorandum of Understanding. U.S. Environmental Protection Agency, Climate Protection Partnerships Division. April 1. www.energystar.gov 
US EPA. 1999. Copier Memorandum of Understanding. U.S. Environmental Protection Agency, Climate Protection Partnerships Division. November 1. www.energystar.gov

US EPA. 2000. Printer/Fax Memorandum of Understanding (Version 3.0.). U.S. Environmental Protection Agency, Climate Protection Partnerships Division. November 1. www.energystar.gov 


\section{Appendix A: Product Summary of Fax Machines}

\begin{tabular}{|c|l|l|l|l|l|c|}
\hline Fax ID No. & Product Category & \multicolumn{1}{|c|}{ Technology } & Manufacturer & Model Number & Price & Fax Speed \\
\hline $\mathbf{1}$ & Fax, Copy & Color Inkjet & Brother & Fax1800c & $\$ 170$ & $33.6 \mathrm{~K}$ bps \\
\hline $\mathbf{2}$ & Fax, Copy & Inkjet & Sharp & UX-P100 & $\$ 80$ & $9.6 \mathrm{~K}$ bps \\
\hline $\mathbf{3}$ & Fax, Copy & Thermal & Panasonic & KX-KHD331 & $\$ 90$ & $9.6 \mathrm{Kdps}$ \\
\hline $\mathbf{4}$ & Fax & Inkjet & Brother & Fax775 & $\$ 100$ & Not available \\
\hline $\mathbf{5}$ & Fax, Copy & Laser & Brother & Fax 2800 & $\$ 250$ & $14.4 \mathrm{~K}$ bps \\
\hline $\mathbf{6}$ & Fax & Inkjet & Brother & Fax 1270e & $\$ 130$ & $14.4 \mathrm{~K}$ bps \\
\hline $\mathbf{7}$ & Fax, Copy & Thermal & Panasonic & KX-FPG371 & $\$ 180$ & $14.4 \mathrm{~K}$ bps \\
\hline $\mathbf{8}$ & Fax, Copy & Thermal & Panasonic & KX-FHD351 & $\$ 180$ & $14.4 \mathrm{~K}$ bps \\
\hline $\mathbf{9}$ & Fax, Copy & Inkjet & Hewlett Packard & C8580A & $\$ 150$ & $14.4 \mathrm{~K}$ bps \\
\hline $\mathbf{1 0}$ & Fax & Baser & Brother & Fax 4100 & $\$ 400$ & $14.4 \mathrm{~K}$ bps \\
\hline $\mathbf{1 1}$ & Fax, Copy & Inkjet & Sharp & $\$ 130$ & $14.4 \mathrm{~K}$ bps \\
\hline
\end{tabular}




\section{Appendix B: Metering Protocol}

\section{Power Meters}

We used two power meters: Electronic Product Design Incorporated Model PLM1-PK and PLM-1LP. Operating power for the meters is 120 volts. Below are the specifications for the meters.

\begin{tabular}{|l|l|l|}
\hline & PLM-1LP & PLM-1PK \\
\hline RMS Voltage & $0.1-140$ volts & $0.1-140$ volts \\
RMS Current & 0.0010 to $4.000 \mathrm{amps}$ & 0.001 to $15.000 \mathrm{amps}$ \\
Volt-Amps & 0.01 to 560.00 & 0.1 to 2100.0 \\
Real Power (Watts) & 0.01 to 560.00 & 0.1 to 2800.0 \\
Time Averaged Watts & 0.01 to 560.00 & - \\
Peak Voltage & 0.1 to 200.0 volts & 0.1 to 200.0 volts \\
Peak Current & 0.10 to 10.00 amps & $0.1-100.0$ amps \\
Peak Power (Watts) & 1 to 2,000 & 1 to 20,000 \\
Power Factor & 0.01 to 1.00 & 0.01 to 1.00 \\
Watt-Hours & 0 to $999,999.999$ & 0 to $999,999.999$ \\
Hours & 0.01 to 600.00 hours & 0.01 to 655.36 hours \\
\hline
\end{tabular}

\section{General}

After getting permission of the primary user or retailer, meter the equipment when it is not being used. Record the manufacturer/brand, date of manufacturer (if no date, inquire with retailer about acquisition date), product technology, model number, retail price (if in an office, inquire about the product cost), and if the product has an ENERGY STAR label. Also record information related to power supplies including whether or not the power supply is internal/external and if external, the information presented on the power supply such as manufacturer, amps, $\mathrm{Hz}$, voltage and wattage (if present). If the power supply is internal and information related to the internal power supply is presented on the back of the equipment, also record this information.

Record the power state in which the equipment is found, based on the power indicator, which is usually dark when off, green when on and amber and/or blinking when in low power mode. Displays typically also indicate the power status of the device. Before metering record the original power management settings for the device. Record how to access the power management settings (i.e. through the menu, if it is an auto off, if on/idle=standby, etc.). Also record the initial delay setup times for which the product was set to initiate sleep. Record any unusual circumstances about the equipment or setup that could affect its power consumption or measurement.

For products with ENERGY STAR labels on the device, take a digital photograph of those products. Also, for products with different labels or promotional stickers outside of the normal nameplate logos and safety labels, also take digital photographs of those labels and product stickers. 
Plug the power line meter (PLM) into an outlet and verify that the baseline power readout is zero watts; if the reading is not zero, subtract this measurement from subsequent measurements. For inkjet/bubblejet printers and standalone fax machines, use the 3A meter. For printer based MFD, laser printers, Fax/copy, digital copiers, and personal copiers, use the $15 \mathrm{~A}$ meter.

Now you are ready to measure active, on, off and low-power levels, using the following guidelines. Whenever the equipment enters a new power level, wait at least 15 seconds for the reading to stabilize, than observe the readout for 30 seconds. For printers that are observed to cycle in the standby or sleep mode, obtain logged data for 1 hour of low power consumption. Record the range and mode (most frequent number) to $0.1 \mathrm{~W}$. For products that take one hour to initiate sleep take an initial on/idle measurement. Take another on/idle measurement after 0.5 hours. Record both measurements. For products where logged data was obtained calculate average value for each level of consumption obtained.

For each low power level measured, record the following,

- Whether the low-power level is activated automatically (via delay settings in the control panel) or manually (requiring that the user select the low-power level from a menu) and if there is an auto off function for copiers. Low-power levels that can be activated manually or automatically should be initiated and measured both ways. Record if there is no low power state (i.e. only an on/idle mode).

- Appearance of the power indictor while the unit is in the low-power level and the display while the product is in the low power level.

- The minimum level of action required to wake the unit up from its low-power level.

- The measured time (in seconds) it takes the equipment to fully recover from the off power level and the low power level.

\section{Printers and Printer-based MFD ${ }^{7}$}

For most inkjet printers, there is no low power mode activated through PM setting. The only power states to measure are off, on-idle, and active.

\section{Spot metering}

Turn printer off (if not already off) and unplug unit from wall socket. Plug unit into PLM, allow meter to stabilize for 30 seconds and measure off power. Measure active power by printing a demo page.

To Measure low power mode, in the menu settings, enable any PM options that are not already enabled. For the low power-level, select the minimum delay setting so that the printer enters that low-power level as soon as possible after cessation of user activity. Wait for the printer to enter the low-power level and measure printer power as described

\footnotetext{
${ }^{7}$ Covers inkjet printers, bubblejet printers, laser printers, inkjet printer-based all-in-ones (printers, copiers, faxes, scanners), and laser printer-based all-in-ones
} 
above. Record the appearance of the printer power indicator and/or display, then initiate and record the wake event and recovery time.

After measuring all power levels, printer metering is complete. Restore as-found PM settings in the menu settings. Turn the printer off, unplug it from the PLM and connect it to the power source.

\section{Time series}

If the printer is not already off, turn the printer off. Plug the printer into the PLM and connect plm to logging computer. Measure the printer in off power. Turn the printer on (record time to recover). When printer has recovered and power light indicator is stable for 30 seconds. Measure active power by printing 20 copies of standard page for $\mathrm{B} \& \mathrm{~W}$, and color, if color printing is available.

To Measure low power mode, in the menu settings, enable any PM options that are not already enabled. For the low power-level, select the minimum delay setting so that the printer enters that low-power level as soon as possible after cessation of user activity. Wait for the printer to enter the low-power level and measure printer power as described above. Record the appearance of the printer power indicator and/or display, then initiate and record the wake event and recovery time. Because some devices have been found to have cyclic standby power levels, each device will be observed for five minutes after the power level reached standby level following startup. If within that time the device displays cycling, high, low and modal values will be obtained (where possible) for both the low and high standby levels.

After measuring all power levels, printer metering is complete. Restore as-found PM settings in the menu settings. Turn the printer off, unplug it from the PLM and connect it to the power source.

Record additional product information according to the table in this protocol. If information is not available at the retail location, look at manufacturer's websites for the additional information.

\section{Facsimiles $^{8}$}

Because fax machine low power settings are often difficult to locate in the menus, it can be a good idea to identify products in retail settings prior to metering and identify procedure for initiating low power modes before metering. You can identify these models by looking on manufacturer's websites and in product brochures and manuals before going into retail stores and metering.

Typically, the fax machine does not have an off power button. Disconnect the fax machine from the power source. Plug the fax machine into the PLM. If unit has off switch, measure unit for 30 seconds in off mode. Turn unit on (if switch present). When fax machine has recovered (record recovery time) and power light indicator or display is

\footnotetext{
${ }^{8}$ Cover fax and fax/copy products
} 
stable for 30 seconds, record fax power in on-idle mode. According to most manufacturer's product manuals, on-idle when the product is displaying date and time is what the manufacturers refer to as "standby".

If the product has a low power mode, enable any PM options that are not already enabled. Select the minimum delay setting so that the fax automatically enters that low-power level as soon as possible. Wait for the fax to enter the low-power level and measure fax power as described above. Record the appearance of the fax, then initiate and record the wake event and recovery time. Once metering is complete, restore PM settings. If switch present turn unit off (if presence of off switch) and unplug from PLM. Plug unit back into wall socket.

\section{Personal Copiers}

If the copier is not already off, turn the copier off. Plug the copier into the PLM and connect plm to logging computer. Measure the copier in off power. Turn the copier on (record time to recover). When copier has recovered and power light indicator is stable for 30 seconds. Measure active power by copying 20 copies of standard page for B\&W, and color, if color copying is available.

To Measure low power mode, in the menu settings, enable any PM options that are not already enabled. For the low power-level, select the minimum delay setting so that the copier enters that low-power level as soon as possible after cessation of user activity. Wait for the copier to enter the low-power level and measure copier power as described above. Record the appearance of the copier power indicator and/or display, then initiate and record the wake event and recovery time. Because some devices have been found to have cyclic standby power levels, each device will be observed for five minutes after the power level reached standby level following startup. If within that time the device displays cycling, high, low and modal values will be obtained (where possible) for both the low and high standby levels.

After measuring all power levels, copier metering is complete. Restore as-found PM settings in the menu settings. Turn the copier off, unplug it from the PLM and connect it to the power source. 
Data Collection Table

\begin{tabular}{|l|c|c|c|c|c|}
\cline { 2 - 6 } \multicolumn{1}{c|}{} & Inkjet Printer & Laser Printer & Copier & Fax & Printer MFD \\
\hline Product Category & $\mathbf{X}$ & $\mathbf{X}$ & $\mathbf{X}$ & $\mathbf{X}$ & $\mathbf{X}$ \\
\hline Technology & $\mathbf{X}$ & $\mathbf{X}$ & $\mathbf{X}$ & $\mathbf{X}$ & $\mathbf{X}$ \\
\hline Manufacturer & $\mathbf{X}$ & $\mathbf{X}$ & $\mathbf{X}$ & $\mathbf{X}$ & $\mathbf{X}$ \\
\hline Product Category & $\mathbf{X}$ & $\mathbf{X}$ & $\mathbf{X}$ & $\mathbf{X}$ & $\mathbf{X}$ \\
\hline Model & $\mathbf{X}$ & $\mathbf{X}$ & $\mathbf{X}$ & $\mathbf{X}$ & $\mathbf{X}$ \\
\hline Manufacture Date & $\mathbf{X}$ & $\mathbf{X}$ & $\mathbf{X}$ & $\mathbf{X}$ & $\mathbf{X}$ \\
\hline Price & $\mathbf{X}$ & $\mathbf{X}$ & $\mathbf{X}$ & $\mathbf{X}$ & $\mathbf{X}$ \\
\hline Color Print Speed & $\mathbf{X}$ & $\mathbf{X}$ & & & $\mathbf{X}$ \\
\hline B/W Print Speed & $\mathbf{X}$ & $\mathbf{X}$ & $\mathbf{X}$ & & $\mathbf{X}$ \\
\hline Photo Speed & $\mathbf{X}$ & & & & \\
\hline Copy Speed & & & $\mathbf{X}$ & $\mathbf{X}$ & $\mathbf{X}$ \\
\hline Fax Speed & & & $\mathbf{X}$ & $\mathbf{X}$ & $\mathbf{X}$ \\
\hline Print Resolution & $\mathbf{X}$ & $\mathbf{X}$ & $\mathbf{X}$ & & $\mathbf{X}$ \\
\hline Scan Resolution & & & $\mathbf{X}$ & & $\mathbf{X}$ \\
\hline Connectivity & $\mathbf{X}$ & $\mathbf{X}$ & $\mathbf{X}$ & $\mathbf{X}$ & $\mathbf{X}$ \\
\hline Memory & & & & & \\
\hline Duty Cycle & $\mathbf{X}$ & $\mathbf{X}$ & & & $\mathbf{X}$ \\
\hline Duplex Features & $\mathbf{X}$ & $\mathbf{X}$ & $\mathbf{X}$ & & $\mathbf{X}$ \\
\hline Network (Y/N) & $\mathbf{X}$ & $\mathbf{X}$ & $\mathbf{X}$ & & $\mathbf{X}$ \\
\hline Auto Off(Y/N) & & & $\mathbf{X}$ & & \\
\hline Copy Features & & & $\mathbf{X}$ & & $\mathbf{X}$ \\
\hline E*(Y/N), Type of Label & $\mathbf{X}$ & $\mathbf{X}$ & $\mathbf{X}$ & $\mathbf{X}$ & $\mathbf{X}$ \\
\hline PM Settings and Features & $\mathbf{X}$ & $\mathbf{X}$ & $\mathbf{X}$ & $\mathbf{X}$ & $\mathbf{X}$ \\
\hline
\end{tabular}




\section{Appendix C: Product Summary of Printers}

\begin{tabular}{|c|c|c|c|c|c|c|}
\hline Printer ID No. & Technology & Manufacturer & Product & Model Number & $\begin{array}{l}\text { Manual } \\
\text { Testing }\end{array}$ & Data Logger \\
\hline 1 & Inkjet & Hewlett-Packard & HP DeskJet 845C & C6506A & $X$ & \\
\hline 2 & Inkjet & Lexmark & Lexmark Z23 & None listed & $\mathrm{X}$ & \\
\hline 3 & Inkjet & Epson & Epson Stylus Photo 785 EPX & P270A & $\mathrm{X}$ & \\
\hline 4 & Inkjet & Brother & $\begin{array}{l}\text { Brother MFC 5100C Inkjet } \\
\text { All-in-one }\end{array}$ & MFC 5100C & $\mathrm{X}$ & \\
\hline 5 & Inkjet & Brother & Brother MFC 3100C & MFC 3100C & $\mathrm{X}$ & \\
\hline 6 & Inkjet & Hewlett-Packard & HP DeskJet 3420 & $\mathrm{C} 8947 \mathrm{C}$ & $\mathrm{X}$ & \\
\hline 7 & Inkjet & Canon & Canon i320 Bubblejet & K10217 & $X$ & \\
\hline 8 & Inkjet & Hewlett Packard & HP PSC 750 & $\mathrm{C} 8424 \mathrm{~A}$ & $X$ & \\
\hline 9 & Inkjet & Hewlett Packard & HP Officejet K80 & C6747A & $X$ & \\
\hline 10 & Inkjet & Lexmark & Lexmark X83 & GNZ01 & $\mathrm{X}$ & \\
\hline 11 & Inkjet & Epson & Epson Stylus Photo 820 & P330A & $X$ & \\
\hline 12 & Inkjet & Hewlett-Packard & HP DeskJet 3820 & C8952A & $\mathrm{X}$ & \\
\hline 13 & Inkjet & Epson & Epson Stylus C42UX & B161B & $X$ & \\
\hline 14 & Inkjet & Epson & Epson Stylus CX3200 & C151A & $\mathrm{X}$ & \\
\hline 15 & Inkjet & Hewlett Packard & HP PSC 2110 & C8648A & $X$ & \\
\hline 16 & Inkjet & Epson & Epson Stylus C62 & B162A & $X$ & \\
\hline 17 & Inkjet & Hewlett-Packard & HP Photosmart 7150 & Q1604A & $\mathrm{X}$ & \\
\hline 18 & Inkjet & Lexmark & Lexmark Z45 SE Inkjet & $4111-001$ & $\mathrm{X}$ & \\
\hline 19 & Inkjet & Hewlett-Packard & $\begin{array}{l}\text { HP Business Inkjet (1-5 users) } \\
2230\end{array}$ & $\mathrm{C} 8119 \mathrm{~A}$ & $\mathrm{X}$ & \\
\hline 20 & Inkjet & Hewlett Packard & HPlj 3330 & Not available & & $\mathrm{X}$ \\
\hline 21 & Inkjet & Hewlett Packard & HP 2250TN & Not available & & $\mathrm{X}$ \\
\hline 22 & Inkjet & Hewlett Packard & HP PSC 2210 & C8654A & $X$ & \\
\hline 23 & Inkjet & Lexmark & Lexmark Z55se & 4106-001 & $\mathrm{X}$ & \\
\hline 24 & Inkjet & Hewlett-Packard & HP Photosmart 7550 & Q1605A & $\mathrm{X}$ & \\
\hline 25 & Inkjet & Hewlett-Packard & HP Photosmart 7350 & Q1603A & $\mathrm{X}$ & \\
\hline 26 & Inkjet & Hewlett-Packard & HP DeskJet 5550 & C6487C & $X$ & \\
\hline
\end{tabular}




\begin{tabular}{|c|c|c|c|c|c|c|}
\hline 27 & Inkjet & Canon & Canon i550 Bubblejet & K10220 & $\mathrm{X}$ & \\
\hline 28 & Inkjet & Hewlett Packard & HP Officejet 6110 & Q1636A & $\mathrm{X}$ & \\
\hline 29 & Inkjet & Hewlett Packard & HP Officejet d 135 & C7297A & $\mathrm{X}$ & \\
\hline 30 & Inkjet & Hewlett-Packard & HP DeskJet 6122 & C8954B & $\mathrm{X}$ & \\
\hline 31 & Inkjet & Lexmark & Lexmark Photojet print Z65P & 4107-KP1 & $\mathrm{X}$ & \\
\hline 32 & Inkjet & Epson & Epson Stylus CX5200 & C141A & $\mathrm{X}$ & \\
\hline 33 & Inkjet & Epson & Epson Stylus C82 & B171A & $\mathrm{X}$ & \\
\hline 34 & Laser & Brother & $\begin{array}{l}\text { Brother MFC } 4800 \text { Laser All- } \\
\text { in-one }\end{array}$ & MFC 4800 & $\mathrm{X}$ & \\
\hline 35 & Laser & Hewlett Packard & HP Laserjet 1000 & Q1342A & $\mathrm{X}$ & \\
\hline 36 & Laser & Tektronics & Tecktronics 850 & Not Available & & $\mathrm{X}$ \\
\hline 37 & Laser & Hewlett Packard & HP Laserjet 1200 se & $\begin{array}{l}\text { Nameplate information } \\
\text { not available }\end{array}$ & $\mathrm{X}$ & \\
\hline 38 & Laser & Hewlett Packard & 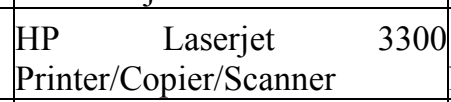 & No nameplate information X & $\mathrm{X}$ & \\
\hline 39 & Laser & Minolta & $\begin{array}{l}\text { Minolta QMS Magicolor } 2300 \\
\text { Desktop Laser }\end{array}$ & MC2300 DC & $\mathrm{X}$ & \\
\hline 40 & Laser & Xerox & Xerox 6200 & Not Available & $\mathrm{X}$ & $\mathrm{X}$ \\
\hline 41 & Laser & Hewlett Packard & $\begin{array}{l}\text { HP Laserjet } 2500 \text { Color } \\
\text { Printer }\end{array}$ & $\begin{array}{l}\text { Nameplate information } \\
\text { not available }\end{array}$ & $\mathrm{X}$ & \\
\hline 42 & Laser & Tektronics & Tektronics 750 & Not Available & $\mathrm{X}$ & $\mathrm{X}$ \\
\hline 43 & Laser & Hewlett Packard & HP 4550 & C7085A & $\mathrm{X}$ & $\mathrm{X}$ \\
\hline 44 & Laser & Hewlett Packard & HP 4550DN & Not Available & $\mathrm{X}$ & $\mathrm{X}$ \\
\hline 45 & Laser & Brother & $\begin{array}{l}\begin{array}{l}\text { Brother } \\
\text { Laser }\end{array} \\
\text { HL-5040 Personal }\end{array}$ & HL-50 & $\mathrm{X}$ & \\
\hline 46 & Laser & Hewlett Packard & HP 4600 & C9661A & & $\mathrm{X}$ \\
\hline 47 & Laser & $\mathrm{HP}$ & $4000 \mathrm{~N}$ & C4120AABM & & $\mathrm{X}$ \\
\hline 48 & Laser & Brother & Brother HL-1850 Laser & HL-18 & $\mathrm{X}$ & \\
\hline 49 & Laser & HP & $2200 \mathrm{dn}$ & C $7063 \mathrm{~A}$ & & $\mathrm{X}$ \\
\hline 50 & Laser & Lexmark & Lexmark T520 & Not Available & & $\mathrm{X}$ \\
\hline
\end{tabular}




\begin{tabular}{|l|l|l|l|l|l|l|}
\hline $\mathbf{5 1}$ & Laser & Xerox & Xerox 1235 & Not Available & X & X \\
\hline $\mathbf{5 2}$ & Laser & HP & 4100 dn & Not Available & X \\
\hline $\mathbf{5 3}$ & Laser & Lexmark & Lexmark T620 & Not Available & X \\
\hline $\mathbf{5 4}$ & Laser & Hewlett Packard & HP 8150 & C 4267 A & X \\
\hline $\mathbf{5 5}$ & Laser & Hewlett Packard & HP 8100 & C4214A & X & X \\
\hline & & & $\begin{array}{l}\text { Nameplate information } \\
\text { not available }\end{array}$ & \\
& & & C8521A & & \\
\hline $\mathbf{5 6}$ & Laser & Hewlett Packard & HP Laserjet 4200 & & X \\
\hline
\end{tabular}

Notes:

1. The Tektronics 750 was spot metered and time-series metered during a one hour test. Measurements in this report reflect data collected during the spot-metering testing for active, sleep and off power.

2. The HP 8100 was metered spot metered and time-series metered during a one hour test. Measurements for active and off power reflect data collected during the spot metering test. Standby and sleep power was collected with the time-series logger.

3. The HP 4550 was metered was spot metered and time-series metered during a one hour test. Active power and off power reflect data collected during the spot metering test. Ready and sleep power measured with the time series data logger.

4. The HP 4550dn was metered was spot metered and time-series metered. Sleep power reflects data collected through spot metering.

5. Xerox 1235 was metered both spot metered and with the time-series metering. Active and off reflect spot metering, standby and sleep power reflect measurements taken with time-series testing.

6. Xerox 6200 was metered both spot and with the time-series testing. Active and off reflect measurements obtained through spot metering. Standby and sleep reflect measurements from time-series testing. 


\section{Appendix D: Product Summary of Copiers}

\begin{tabular}{|c|c|c|c|c|c|c|}
\hline ID & Technology & Manufacturer & Product & Model Number & $\begin{array}{l}\text { Manual } \\
\text { Testing }\end{array}$ & Datalogger \\
\hline 1 & $\begin{array}{l}\text { Electrostatic } \\
\text { transfer }\end{array}$ & Canon & \begin{tabular}{|l|} 
Canon Personal Desktop \\
Portable 428 Color Copier
\end{tabular} & HF135000 & & \\
\hline 2 & $\begin{array}{l}\text { Electrostatic } \\
\text { transfer }\end{array}$ & Canon & $\begin{array}{l}\text { Canon Personal } 940 \text { Copier } \\
\text { (BW) }\end{array}$ & F138400 & $\mathrm{X}$ & \\
\hline 3 & Laser & Canon & \begin{tabular}{|l|} 
Canon Imageclass D660 \\
Digital Copier
\end{tabular} & No nameplate information & $\mathrm{X}$ & \\
\hline 4 & Laser & Canon & $\begin{array}{l}\text { Canon Imagiclass } \\
\text { Digital Printer/Copier }\end{array}$ & No tag on eqp & $\mathrm{X}$ & \\
\hline 5 & Laser & Sharp & $\begin{array}{l}\text { Sharp Digital Laser Copier } \\
\text { AL-1530CS }\end{array}$ & AL 1530CS & $\mathrm{X}$ & \\
\hline 6 & Laser & Sharp & $\begin{array}{l}\text { Sharp Digital Laser Copier } \\
\text { AL-1551CS }\end{array}$ & AL 1551CS & $\mathrm{X}$ & \\
\hline 7 & Laser & Sharp & $\begin{array}{l}\text { Sharp Digital Laser Copier } \\
\text { AL-1540C }\end{array}$ & AL $1540 \mathrm{C}$ & $\mathrm{X}$ & \\
\hline 8 & Inkjet & Hewlett Packard & $\begin{array}{l}\text { HP } 310 \text { Digital Inkjet Color } \\
\text { Copier }\end{array}$ & $\mathrm{C} 8424 \mathrm{~A}$ & $\mathrm{X}$ & \\
\hline 9 & Laser & Kyocera/Mita & Kyocera 1810 & No tag on eqp & & $\mathrm{X}$ \\
\hline 10 & Laser & Kyocera/Mita & Kyocera 4530 & No nameplate information & & $\mathrm{X}$ \\
\hline 11 & Laser & Kyocera/Mita & Kyocera 4530 (2nd unit) & No nameplate information & & $\mathrm{X}$ \\
\hline 12 & Laser & Kyocera/Mita & Kyocera 6330 & No nameplate information & & $\mathrm{X}$ \\
\hline 13 & Laser & Kyocera/Mita & Kyocera 5530 & No nameplate information & & $\mathrm{X}$ \\
\hline 14 & Laser & Kyocera/Mita & Kyocera 3530 & No nameplate information & & $\mathrm{X}$ \\
\hline 15 & Laser & Kyocera/Mita & Kyocera 3130 & No nameplate information & & $\mathrm{X}$ \\
\hline 16 & Laser & Kyocera/Mita & Kyocera 6230 & No nameplate information & & $\mathrm{X}$ \\
\hline 17 & Laser & Canon & Canon 6050 & No nameplate information & & $\mathrm{X}$ \\
\hline 18 & Laser & Xerox & Xerox 555 & No nameplate information & & $\mathrm{X}$ \\
\hline 19 & Laser & Hewlett Packard & HP 8550 & No nameplate information & & $\mathrm{X}$ \\
\hline
\end{tabular}




\section{Appendix E: Detailed Tables}




\section{Inkjets}

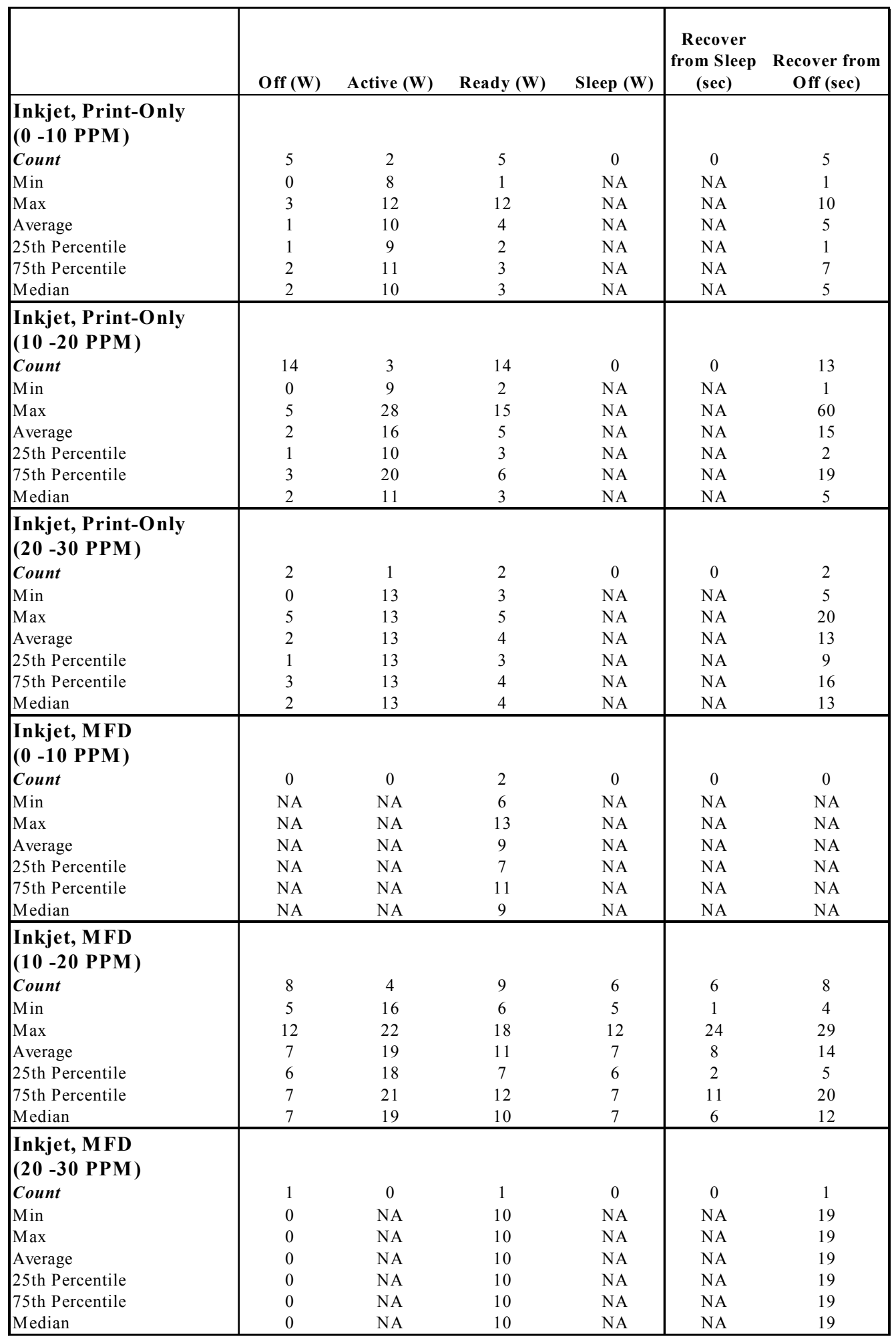


Monochrome Laser Printers

\begin{tabular}{|c|c|c|c|c|c|c|}
\hline & Off $(W)$ & Active (W) & Ready (W) & Sleep (W) & $\begin{array}{c}\text { Recover } \\
\text { from Sleep } \\
\text { (sec) }\end{array}$ & $\begin{array}{l}\text { Recover from } \\
\text { Off (sec) }\end{array}$ \\
\hline \multicolumn{7}{|c|}{$\begin{array}{l}\text { BW Laser Printers } \\
(0 \text {-10 PPM) }\end{array}$} \\
\hline Count & 0 & 0 & 2 & 1 & 1 & 0 \\
\hline Min & NA & NA & 6 & 9 & 5 & NA \\
\hline Max & NA & NA & 9 & 9 & 5 & NA \\
\hline Average & NA & NA & 7 & 9 & 5 & NA \\
\hline 25th Percentile & NA & NA & 7 & 9 & 5 & NA \\
\hline 75th Percentile & NA & NA & 8 & 9 & 5 & NA \\
\hline Median & NA & NA & 7 & 9 & 5 & NA \\
\hline \multicolumn{7}{|c|}{$\begin{array}{l}\text { BW Laser Printers } \\
(10 \text {-20 PPM) }\end{array}$} \\
\hline Count & 5 & 3 & 7 & 5 & 4 & 5 \\
\hline Min & 0 & 264 & 4 & 4 & 0 & 10 \\
\hline Max & 0 & 322 & 83 & 18 & 25 & 46 \\
\hline Average & 0 & 284 & 20 & 9 & 11 & 26 \\
\hline 25th Percentile & 0 & 266 & 7 & 7 & 1 & 20 \\
\hline 75th Percentile & 0 & 295 & 14 & 11 & 18 & 30 \\
\hline Median & 0 & 267 & 10 & 8 & 9 & 24 \\
\hline \multicolumn{7}{|c|}{$\begin{array}{l}\text { BW Laser Printers } \\
(20 \text {-30 PPM) }\end{array}$} \\
\hline Count & 2 & 2 & 2 & 2 & 2 & 2 \\
\hline Min & 0 & 669 & 19 & 14 & 0 & 46 \\
\hline Max & 0 & 903 & 67 & 19 & 1 & 60 \\
\hline Average & 0 & 786 & 43 & 16 & 1 & 53 \\
\hline 25th Percentile & 0 & 727 & 31 & 15 & 0 & 50 \\
\hline 75th Percentile & 0 & 844 & 55 & 18 & 1 & 57 \\
\hline Median & 0 & 786 & 43 & 16 & 1 & 53 \\
\hline \multicolumn{7}{|c|}{$\begin{array}{l}\text { BW Laser Printers } \\
\text { (30 -44 PPM) }\end{array}$} \\
\hline Count & 3 & 2 & 3 & 3 & 3 & 2 \\
\hline Min & 0 & 931 & 19 & 18 & 30 & 42 \\
\hline Max & 0 & 1320 & 121 & 36 & 42 & 48 \\
\hline Average & 0 & 1125 & 86 & 29 & 38 & 45 \\
\hline 25th Percentile & 0 & 1028 & 68 & 25 & 36 & 44 \\
\hline 75th Percentile & 0 & 1223 & 119 & 34 & 42 & 47 \\
\hline Median & 0 & 1125 & 117 & 32 & 41 & 45 \\
\hline \multicolumn{7}{|c|}{$\begin{array}{l}\text { BW Laser Printers } \\
(+44 \text { PPM })\end{array}$} \\
\hline Count & 1 & 1 & 1 & 1 & 1 & 1 \\
\hline Min & 0 & 637 & 230 & 40 & 74 & 111 \\
\hline Max & 0 & 637 & 230 & 40 & 74 & 111 \\
\hline Average & 0 & 637 & 230 & 40 & 74 & 111 \\
\hline 25th Percentile & 0 & 637 & 230 & 40 & 74 & 111 \\
\hline 75th Percentile & 0 & 637 & 230 & 40 & 74 & 111 \\
\hline Median & 0 & 637 & 230 & 40 & 74 & 111 \\
\hline
\end{tabular}




\section{Color Laser Printers}

\begin{tabular}{|c|c|c|c|c|c|c|}
\hline & Off $(W)$ & Active (W) & Ready (W) & Sleep (W) & $\begin{array}{c}\text { Recover } \\
\text { from Sleep } \\
\text { (sec) }\end{array}$ & $\begin{array}{l}\text { Recover from } \\
\text { Off (sec) }\end{array}$ \\
\hline \multicolumn{7}{|c|}{$\begin{array}{l}\text { Color Laser Printers } \\
(0 \text {-10 PPM) }\end{array}$} \\
\hline Count & 5 & 3 & 5 & 4 & 4 & 5 \\
\hline Min & 0 & 385 & 19 & 12 & 45 & 83 \\
\hline Max & 82 & 579 & 137 & 36 & 80 & 240 \\
\hline Average & 16 & 491 & 63 & 27 & 58 & 160 \\
\hline 25th Percentile & 0 & 447 & 20 & 23 & 52 & 119 \\
\hline 75th Percentile & 0 & 544 & 108 & 33 & 61 & 230 \\
\hline Median & 0 & 509 & 30 & 29 & 54 & 129 \\
\hline \multicolumn{7}{|c|}{$\begin{array}{l}\text { Color Laser Printers } \\
(10 \text {-20 PPM) }\end{array}$} \\
\hline Count & 4 & 4 & 4 & 3 & 3 & 3 \\
\hline Min & 0 & 200 & 31 & 18 & 1 & 64 \\
\hline Max & 2 & 713 & 164 & 42 & 38 & 136 \\
\hline Average & 0 & 401 & 95 & 30 & 13 & 103 \\
\hline 25th Percentile & 0 & 289 & 64 & 25 & 1 & 86 \\
\hline 75th Percentile & 0 & 458 & 124 & 36 & 20 & 122 \\
\hline Median & 0 & 345 & 93 & 31 & 1 & 108 \\
\hline
\end{tabular}


